Atmos. Chem. Phys., 17, 10019-10036, 2017

https://doi.org/10.5194/acp-17-10019-2017

(C) Author(s) 2017. This work is distributed under

the Creative Commons Attribution 3.0 License.

\title{
Dynamic consideration of smog chamber experiments
}

\author{
Wayne K. Chuang and Neil M. Donahue \\ Carnegie Mellon University Center for Atmospheric Particle Studies, Pittsburgh, USA \\ Correspondence to: Neil M. Donahue (nmd@andrew.cmu.edu)
}

Received: 5 November 2016 - Discussion started: 9 December 2016

Revised: 17 June 2017 - Accepted: 27 June 2017 - Published: 28 August 2017

\begin{abstract}
Recent studies of the $\alpha$-pinene + ozone reaction that address particle nucleation show relatively high molar yields of highly oxidized multifunctional organic molecules with very low saturation concentrations that can form and grow new particles on their own. However, numerous smogchamber experiments addressing secondary organic aerosol (SOA) mass yields, interpreted via equilibrium partitioning theory, suggest that the vast majority of SOA from $\alpha$-pinene is semivolatile. We explore this paradox by employing a dynamic volatility basis set (VBS) model that reproduces the new-particle growth rates observed in the CLOUD experiment at CERN and then modeling SOA mass yield experiments conducted at Carnegie Mellon University (CMU). We find that the base-case simulations do overpredict observed SOA mass but by much less than an equilibrium analysis would suggest; this is because delayed condensation of vapors suppresses the apparent mass yields early in the chamber experiments. We further find that a second VBS model featuring substantial oligomerization of semivolatile monomers can match the CLOUD growth rates with substantially lower SOA mass yields; this is because the lighter monomers have a higher velocity and thus a higher condensation rate for a given mass concentration. The oligomerization simulations are a closer match to the CMU experiments than the base-case simulations, though they overpredict the observations somewhat. However, we also find that if the chemical conditions in CLOUD and the CMU chamber were identical, substantial nucleation would have occurred in the CMU experiments when in fact none occurred. This suggests that the chemical mechanisms differed in the two experiments, perhaps because the high oxidation rates in the SOA formation experiments led to rapid termination of peroxy radical chemistry.
\end{abstract}

\section{Introduction}

The mass yields of secondary organic aerosols (SOA) under ambient conditions are a central issue in atmospheric chemistry. SOA production from biogenic compounds, especially monoterpenes such as $\alpha$-pinene, has been studied for decades because of its contribution to "blue haze" (Haagen-Smit, 1952) and its potentially large contribution to background aerosol concentrations both in the preindustrial and presentday atmosphere (Kroll and Seinfeld, 2008; Hallquist et al., 2009). Traditional smog-chamber experiments have been interpreted since Odum et al. (1996) in the context of equilibrium partitioning theory (Pankow, 1994). Specifically, the mass yield of SOA in smog-chamber experiments is defined as the mass of SOA formed $\left(C_{\mathrm{OA}}\right)$ divided by the amount of precursor consumed $\left(\Delta C_{\text {prec }}\right)$, measured in micrograms per cubic meter $\left(\mu \mathrm{g} \mathrm{m}^{-3}\right)$. SOA mass yields characteristically increase with increasing $C_{\mathrm{OA}}$, and Odum's key insight was to realize that this was consistent with equilibrium partitioning theory (Pankow, 1994). Furthermore, "Odum plots" of SOA mass yield versus $C_{\mathrm{OA}}$ organized seemingly discordant experimental data and could be interpreted via the now widely used "two-product" equilibrium partitioning model (Odum et al., 1996).

When the equilibrium analysis pioneered by Odum et al. (1996) is used to constrain the volatility of reaction products from systems such as the ozonolysis of $\alpha$-pinene, it generally suggests a high yield of semivolatile products because the SOA mass yields increase as the loading $\left(C_{\mathrm{OA}}\right)$ increases. Because aerosol loading (and product volatility) can span a wide range, the SOA loading axis of the Odum plot is best expressed along a log scale (Donahue et al., 2006; Presto and Donahue, 2006). Smog-chamber experiments have typically covered a mass concentration range of $1 \lesssim C_{\mathrm{OA}} \lesssim 1000 \mu \mathrm{g} \mathrm{m}^{-3}$, with and without inorganic 
seeds to promote condensation of vapors (Odum et al., 1996; Griffin et al., 1999; Cocker et al., 2001; Presto et al., 2005; Presto and Donahue, 2006; Pathak et al., 2007a; Shilling et al., 2008, 2009; Song et al., 2007). These data show little to no mass yield for $C_{\mathrm{OA}} \lesssim 1 \mu \mathrm{g} \mathrm{m}^{-3}$, but for $1 \leq C_{\mathrm{OA}} \leq$ $1000 \mathrm{\mu g} \mathrm{m}^{-3}$, the mass yield increases dramatically. Even studies with high seed surface area (Pathak et al., 2007b; Song et al., 2007) and continuous-flow chambers that should encourage equilibration (Shilling et al., 2009) show mass yields below $10 \%$ at low $C_{\mathrm{OA}}$, though the results of Song et al. (2007) and Shilling et al. (2009) approach $10 \%$.

Equilibrium partitioning analysis relates the volatility of an organic species to $C_{\mathrm{OA}}$ to determine at what loading a given compound will contribute significantly to the SOA mass yield (Presto and Donahue, 2006). For instance, for an aerosol loading, $C_{\mathrm{OA}}=10 \mu \mathrm{g} \mathrm{m}^{-3}$, an organic species with a volatility of $C^{*}=10 \mu \mathrm{g} \mathrm{m}^{-3}$ will partition $50 \%$ into the gas phase and $50 \%$ into the (organic) particle phase at equilibrium. If the loading were 10 times lower, with $C_{\mathrm{OA}}=$ $1 \mu \mathrm{g} \mathrm{m}^{-3}$, the species would partition $90 \%$ into the gas phase and $10 \%$ into the particle phase. This equilibrium behavior motivates the volatility basis set (VBS), which separates compounds into volatility bins, each an order of magnitude apart (Donahue et al., 2006). In this way, an equilibrium partitioning analysis of smog-chamber data for $\alpha$-pinene SOA parses the yield data to form a distribution of compounds by their volatilities, with few to no compounds with low volatilities, $C^{*} \lesssim 1 \mu \mathrm{g} \mathrm{m}^{-3}$, and most of the mass with volatilities

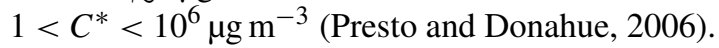

Recent experiments using nitrate-ion clustering chemical ionization mass spectrometry (nitrate CIMS) have revealed the presence of "highly oxidized multifunctional organics" (HOMs) that have been interpreted as extremely lowvolatility organic compounds (ELVOCs) and low-volatility organic compounds (LVOCs, collectively (E)LVOCs) in the VBS nomenclature (Ehn et al., 2014). The molar yield of HOMs was initially estimated to be $7 \pm 3.5 \%$ (Ehn et al., 2014), and their volatilities are thought to be much lower than $10^{-1} \mu \mathrm{g} \mathrm{m}^{-3}$ based on their molecular formulas and assumed structures. Volatility calculations using quantum chemistry indicate higher vapor pressures, but in general the HOMs still have volatilities in the LVOC and ELVOC range (Kurtén et al., 2016).

Experiments conducted in the CLOUD chamber at CERN confirmed a wide distribution of HOMs from oxidation of $\alpha$-pinene, especially by ozone, with the estimated volatility in the range $10^{-20} \lesssim C^{*} \lesssim 10^{-2} \mu \mathrm{g} \mathrm{m}^{-3}$ (Tröstl et al., 2016; Kirkby et al., 2016). The nominal HOM molar yields from the CLOUD nitrate-CIMS measurements based on sulfuric acid calibrations were at the low end of prior measurements, near $3.5 \%$ (Kirkby et al., 2016), but flux-balance calculations based on the observed particle growth rates require more than 3 times the mass flux than can be explained by those nominal values. Tröstl et al. (2016) proposed that the clustering efficiency of the nitrate CIMS scales with $C^{*}$ and that the efficiency drops off in the LVOC volatility range. This is plausible because the nitrate CIMS relies on clustering between polar functional groups and the nitrate anion, which broadly corresponds with what makes the compounds have a low vapor pressure and stick to small particles, and also because more volatile species that dominate $(>90 \%)$ the molar product distribution are invisible to the nitrate CIMS. LVOC yields based on this empirically derived clustering efficiency quantitatively explain the observed particle growth rates for $1 \leq d_{\mathrm{p}} \leq 30 \mathrm{~nm}$, both at constant measured HOM concentrations and when the HOM concentrations are rising steadily. Regardless of any theoretical volatilities based on presumed structures, the observations require a relatively large yield of products capable of sticking to very small clusters and driving particle growth. However, with molar yields well over $10 \%$ of the derived mass yields of these highly functionalized ELVOC and LVOC products exceeds $30 \%$.

The high mass yields of (E)LVOC products, based on direct CIMS measurements from Ehn et al. (2014) and both CIMS measurements and dynamic flux balances based on growth rates from Tröstl et al. (2016), appear to contradict the earlier smog-chamber studies of $\alpha$-pinene ozonolysis SOA mass yields. We illustrate this in Fig. 1, where we contrast the VBS equilibrium partitioning analysis carried out by Presto and Donahue (2006) with the equilibrium expectations of the nitrate-CIMS (E)LVOC observations. In the equilibrium analysis we expect rising mass yields where $C^{*} \simeq C_{\mathrm{OA}}$, indicated by the stacked histogram showing $50 \%$ partitioning for bins with $C^{*}=C_{\mathrm{OA}}$ and the black equilibrium partitioning curve. In contrast, if the mass yield of (E)LVOCs is on the order of $30 \%$ and even if they are at the extreme high end of the LVOC range suitable for condensation in Tröstl et al. (2016) with $C^{*} \simeq 10^{-2} \mu \mathrm{g} \mathrm{m}^{-3}$, we would expect the observed mass yields to rise to $30 \%$ by the time $C_{\mathrm{OA}} \geq 10^{-1} \mu \mathrm{g} \mathrm{m}^{-3}$ in an ideal, loss-free chamber at equilibrium, as shown by the solid green curve. There is a vast difference between the two curves. If these (E)LVOC products exist at such high mass yields, the simple question is thus: why do they not appear as high mass yields at low $C_{\mathrm{OA}}$ in the Odum plots from SOA experiments? There are several possibilities:

1. dynamic effects could delay condensation and thus bias the observed mass yields low for a given amount of precursor loss;

2. condensible vapor loss to the chamber walls could bias the observed SOA mass yields low;

3. oligomerization and not direct condensation of (E)LVOCs could explain some of the CLOUD growthrate observations, with uncertain effects on the SOA chamber mass yields;

4. high oxidation rates in the SOA chambers could interfere with HOM formation via the peroxy-radical autooxidation mechanism. 


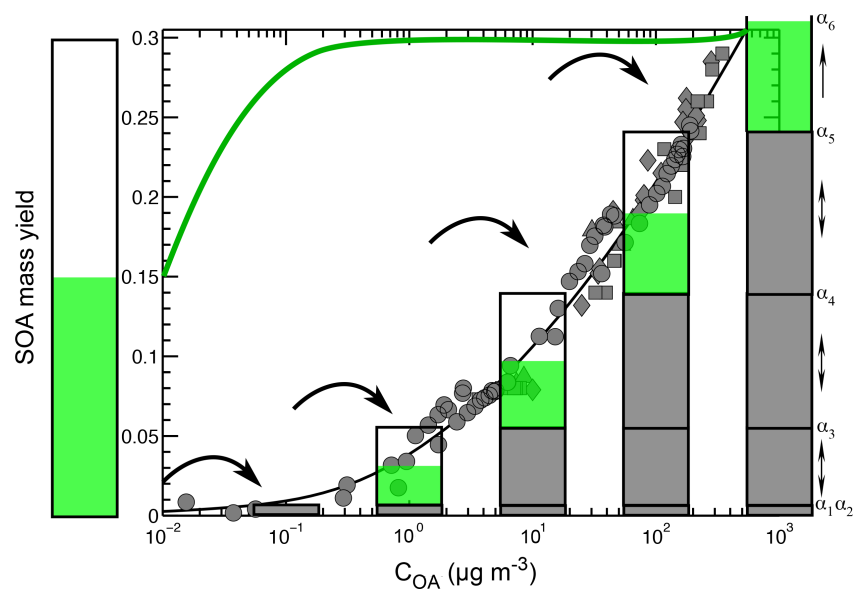

Figure 1. Apparent contradiction between CIMS (E)LVOC measurements and chamber SOA mass yields. A VBS equilibrium partitioning analysis for $\alpha$-pinene ozonolysis SOA compared with equilibrium partitioning expected from CIMS observations showing high mass yields of extremely low-volatility (E)LVOC products. Vertical bars represent mass yields in volatility bins, with filled gray representing species with $C^{*} \ll C_{\mathrm{OA}}$ and green under clear representing 50:50 partitioning of species with $C^{*} \simeq C_{\mathrm{OA}}$. Data and an equilibrium VBS analysis are shown within the frame, while nominal equilibrium partitioning for a single LVOC constituent with a mass yield of 0.3 and $C^{*}=0.01 \mu \mathrm{g} \mathrm{m}{ }^{-3}$ is shown with the offset bar and the green curve. Black arrows denote the complete partitioning of lower volatility products when the total aerosol mass increases by an order of magnitude. The $\alpha$ symbols on the right side denote the yields derived for each subsequent volatility bin. The gap between the black and green curves represents the paradox motivating this paper. Adapted from Presto and Donahue (2006).

In the equilibrium partitioning interpretation, HOMs would instantly condense into the particle phase and show a high (E)LVOC mass yield at low aerosol loading. However, barriers to condensation, such as the Kelvin effect, a low mass accommodation coefficient, or simply a low aerosol surface area, could delay the condensation. The new mass would thus not appear in the condensed phase until more $\alpha$-pinene had reacted, thus lowering the empirical (E)LVOC mass yield. Further, if condensation to suspended particles is low, vapor wall losses may be high (Matsunaga and Ziemann, 2010; Ye et al., 2016a; Trump et al., 2016). Also, while the growthrate data demand that the eventual reaction products have a very low volatility, it is possible that condensedphase chemistry ("oligomerization"; Kalberer et al., 2004; Tolocka et al., 2004) could produce ELVOC products in the CLOUD chamber on a timescale of several hours, driving the $2-6 \mathrm{~nm} \mathrm{~h}^{-1}$ growth rates, but be less evident in chamber SOA experiments where typical conditions involve $\alpha$ pinene oxidation in well under an hour and growth rates above $100 \mathrm{~nm} \mathrm{~h}^{-1}$. Finally, those high oxidation rates in the chamber experiments could interfere with the $\mathrm{RO}_{2}$ autooxidation chemistry (Crounse et al., 2013; Ehn et al., 2014;
Rissanen et al., 2014) by shortening the $\mathrm{RO}_{2}$ bimolecular lifetime, thus sharply reducing the (E)LVOC mass yields in the SOA chamber experiments.

In this study, we begin by modeling aerosol growth dynamically within a VBS framework. Our objective is to explore whether the mass yields required to explain the growth rates observed in CLOUD do indeed overpredict the SOA chamber observations, as suggested by Fig. 1, or whether some combination of dynamics, wall losses, and condensedphase chemistry may reconcile this apparent contradiction. Because of this, we shall consider only condensible products required to explain the CLOUD growth-rate observations (consisting broadly of products with $C^{*} \leq 10^{-2} \mu \mathrm{g} \mathrm{m}{ }^{-3}$, whether formed in the gas or the condensed phase). We shall correct for the temperature difference, as the CLOUD experiments were conducted at $278 \mathrm{~K}$ and typical chamber SOA experiments have been conducted almost $20 \mathrm{~K}$ higher in temperature (corresponding to approximately a 1-decade shift in volatility toward higher values in the SOA chamber experiments). Besides that, however, we shall not model production or condensation of any SVOC products (other than reactive monomers that ultimately oligomerize). We are thus completely neglecting any SVOC monomers, despite considerable evidence that at least one-third and maybe much more of the total SOA from $\alpha$-pinene is semivolatile (Robinson et al., 2013; Ehn et al., 2014; Ye et al., 2016b). The question is only whether this reduced set of (E)LVOC products overpredicts SOA chamber mass yield experiments; any underprediction would presumably be due to condensation of SVOCs in those experiments.

Recent studies imply that a dynamic approach is necessary to capture the interactions between the organics in the vapor phase and the suspended phase (McVay et al., 2014, 2016), and the loss of vapors and particles to the chamber walls (Zhang et al., 2014). Because condensation is not instantaneous, some condensible vapors are lost to the walls instead of settling onto particles. The dynamic model accounts for the time it takes for vapors to interact with particles and condense, or hit the chamber wall and become absorbed by the Teflon.

We can use the model to explore how changes in chamber experiment parameters can change the production (SOA mass yields) of organic aerosols. The production of particle mass depends on the ratio of the particle condensation sink (CS) to the wall-loss sink. The particle condensation sink scales approximately proportionally with particle surface area. Therefore, to decrease the wall loss of condensible vapors, chamber experiments often use ammonium sulfate seeds to encourage condensation as opposed to relying on nucleation, which can result in high wall loss of condensible vapors early in experiments when the nucleated particle condensation sink is very low (Kroll and Seinfeld, 2005).

Condensation seeds in chamber experiments are often polydisperse, spanning a wide size range, over an order of magnitude or more. At any point in time, each particle size 
has a different condensation sink, which affects the growth rate of the particle. This complicates calculations, as each particle would have a different growth rate and also (transiently) a different composition due to different ratios of surface area to volume. The polydispersity may also have implications in particle-phase chemistry (Shiraiwa et al., 2013), though that is not explored here. Saleh et al. (2013) showed that it is possible to use a monodisperse population with the size of a condensation sink diameter to approximate the dynamic behavior of a polydisperse aerosol suspension. We utilize a condensation sink diameter to compare polydisperse and monodisperse versions of our dynamic VBS model, and confirm that the condensation sink diameter provides a good approximation. We also look at how changes in the ratio between the particle condensation sink and the vapor wall loss affects production of suspended organic aerosol.

\section{Methods}

\subsection{Mathematical background}

We modeled the production of $\alpha$-pinene SOA using a dynamic one-dimensional VBS, meaning that we treat volatility only and not the composition of the organics. This was previously discussed in the supplemental material for Tröstl et al. (2016), but here we summarize the essential features. The VBS product distribution spans a volatility range $10^{-8} \leq C^{*} \leq 10^{-1} \mu \mathrm{g} \mathrm{m}^{-3}$, covering extremely lowvolatility to low-volatility organic compounds.

Interactions between the bulk vapors and suspended particles, and between chamber walls, are described by a set of ODEs (ordinary differential equations) for each volatility bin $i$ :

$$
\begin{aligned}
\frac{\mathrm{d} C_{i}^{\mathrm{v}}}{\mathrm{d} t} & =P_{i}^{\mathrm{prec}}-\Phi_{i}^{\mathrm{v}, \mathrm{s}}-\Phi_{i}^{\mathrm{v}, \mathrm{t}}, \\
\frac{\mathrm{d} C_{i}^{\mathrm{s}}}{\mathrm{d} t} & =\Phi_{i}^{\mathrm{v}, \mathrm{s}}-\Phi_{i}^{\mathrm{s}, \mathrm{d}}, \\
\frac{\mathrm{d} C_{i}^{\mathrm{t}}}{\mathrm{d} t} & =\Phi_{i}^{\mathrm{v}, \mathrm{t}}, \\
\frac{\mathrm{d} C_{i}^{\mathrm{d}}}{\mathrm{d} t} & =\Phi_{i}^{\mathrm{s}, \mathrm{d}},
\end{aligned}
$$

where superscripts identify reservoirs: $\mathrm{v}$ is vapor, $\mathrm{s}$ is suspended particles, $t$ is teflon(wall)-absorbed vapors, and $d$ is wall-deposited particles. The superscript order is a transfer of mass from the first to the second reservoir. The term $P_{i}^{\text {prec }}$ denotes the production of vapors through $\alpha$-pinene ozonolysis, and is distributed according to the mass yield for each VBS bin. Vapor-phase HOMs generated through oxidation of $\alpha$-pinene either condense onto suspended particles $\left(\Phi_{i}^{\mathrm{v}, \mathrm{s}}\right)$ or are irreversibly lost to the walls $\left(\Phi_{i}^{\mathrm{v}, \mathrm{t}}\right)$. Vapor wall loss is a first-order loss rate $\Phi_{i}^{\mathrm{v}, \mathrm{t}}=k^{\mathrm{v}, \mathrm{t}} C_{i}^{\mathrm{v}}$ with a timescale of $10 \mathrm{~min}$ (Ye et al., 2016a; Krechmer et al., 2016; Trump et al., 2016).
This is currently assumed to be irreversible, due to the low volatility of the HOMs and the high effective saturation concentration of the walls (McVay et al., 2016).

A major difference between the CLOUD experiment and SOA production experiments in smog chambers is that in CLOUD the collision frequency (condensation sink) of vapors to the walls typically exceeds the suspended condensation sink, whereas in most chamber SOA experiments the suspended condensation sink exceeds the wall collision frequency. Also, CLOUD is stainless steel whereas most SOA smog chambers are Teflon; especially on the metal surfaces, it is possible that reactive uptake (i.e., decarboxylation) is important. However, in each case we model the vapor wall loss as irreversible. We do not treat reversible sorption to the Teflon in this work as proposed by Matsunaga and Ziemann (2010) because our objective is to identify the maximum possible wall interference, and in any event the (E)LVOCs have a very low equilibrium vapor concentration over the walls (Krechmer et al., 2016). Organics in the suspended phase can evaporate into the bulk vapor $\left(-\Phi_{i}^{\mathrm{v}, \mathrm{s}}\right)$; alternatively, the particle itself with its mix of organics and seed can be irreversibly lost to the walls. This is determined by data on the first-order loss rate of SOA in the chamber $\left(\Phi_{i}^{\mathrm{s}, \mathrm{d}}=k^{\mathrm{s}, \mathrm{d}} C_{i}^{\mathrm{s}}\right)$.

\subsection{Experimental data}

In a typical smog-chamber SOA formation experiment, ammonium-sulfate seeds are first injected into a cleaned empty chamber to provide a condensation sink and also to constrain the particle wall loss rate constant. Then $\alpha$-pinene and ozone are added, producing HOMs that condense to the walls or seeds. For the experiments we explicitly model here, the suspended particle evolution was monitored with a scanning mobility particle sizer (SMPS), which measures particle volume but does not differentiate between organics and seeds. In order to separate the two, we rely on the seed loss rate measured prior to the injection of $\alpha$-pinene and extrapolate the seed concentration subsequent to the injection. This results in minor discrepancies between the data and the model concerning the mass of seeds in the chamber, but does not have a major effect on our overall conclusions. Because of the many time-dependent influences, such as wall losses and delays to condensation, we shall directly compare measured to modeled suspended-particle mass (i.e., without any wall-loss corrections) to determine whether the CLOUDconstrained products over- or underpredict the chamber SOA results.

The CLOUD chamber experiments are described in detail in Tröstl et al. (2016); we give a brief summary here. Two types of $\alpha$-pinene ozonolysis experiments were conducted: those with increasing HOM concentrations and those with steady-state HOM concentrations. Increasing HOM concentrations were due to steadily increasing $\alpha$-pinene concentrations throughout the experimental run. Steady-state HOM concentrations were achieved by maintaining a constant $\alpha$ - 
pinene level, resulting in a constant HOM concentration. Using the constraints on the aerosol growth rate from both types of experiments, they derived volatility-distributed mass yields of the products that reproduced particle sizes.

To compare the CLOUD (E)LVOC mass yields with smog-chamber experiments, we simulate data from two experiments described by Pathak et al. (2007b), both of which had relatively high initial seed surface area and thus should have had low (E)LVOC vapor wall loss and rapid equilibration. Both experiments were conducted near room temperature, common in many other smog-chamber experiments. Experiment 1 was conducted with $17 \mathrm{ppb} \alpha$-pinene, a constant $250 \mathrm{ppb} \mathrm{O}_{3}$, and $12000 \mathrm{~cm}^{-3}$ ammonium-sulfate seeds. Experiment 2 was conducted with $38.3 \mathrm{ppb} \alpha$-pinene, a constant $250 \mathrm{ppb} \mathrm{O}_{3}$, and $6000 \mathrm{~cm}^{-3}$ ammonium-sulfate seeds. The SMPS data for these experiments show clear volume maxima after SOA condensation as well as periods where particle wall losses clearly dominate; these are essential to constrain the model. The data also show a steady decline in total particle number with no sign of nucleation after the onset of $\alpha$-pinene ozonolysis.

\section{3 (E)LVOC mass yield distribution}

Tröstl et al. (2016) showed that (E)LVOC species observed in the CLOUD experiment at CERN could explain observed growth rates in experiments where particle nucleation and growth was driven exclusively by $\alpha$-pinene ozonolysis. However, the observed growth was substantially faster than the raw nitrate-CIMS measurements could explain, and so those authors hypothesized that LVOC species are inefficiently detected by the nitrate clustering and thus that the actual LVOC concentrations in CLOUD were significantly higher than the nominal concentrations (which are based on a sulfuric acid calibration). Here we shall retain this interpretation, with large LVOC mass yields, as our base case.

To compare the CLOUD results with CMU smog-chamber data, we need to correct for different experimental temperatures because volatility depends strongly on temperature. The CMU smog-chamber experiments were conducted near room temperature; however, the CLOUD chamber experiments were conducted at $278 \mathrm{~K}$. By applying the ClausiusClapeyron equation to the volatility distribution from Tröstl et al. (2016) and assuming an enthalpy of vaporization of $110 \mathrm{~kJ} \mathrm{~mol}^{-1}$ (Bilde and Pandis, 2001; Sheehan and Bowman, 2001; Epstein et al., 2010), we estimate that an increase of $15 \mathrm{~K}$ results in approximately 1 order of magnitude increase in volatility. The resulting mass yield distribution, shown in Fig. 2, is $\{0.011,0.0060,0.0043,0.0044$, $0.0075,0.075,0.12,0.15\}$ for volatility bins $10^{-8} \leq C^{*} \leq$ $10^{-1} \mu \mathrm{g} \mathrm{m}{ }^{-3}$. The dark green portion of the bars corresponds to the mass yields based on nominal nitrate-CIMS measurements, while the light green portion is the additional concentration required to explain the observed growth rates in CLOUD. This distribution (at $278 \mathrm{~K}$ ) reproduces the parti-

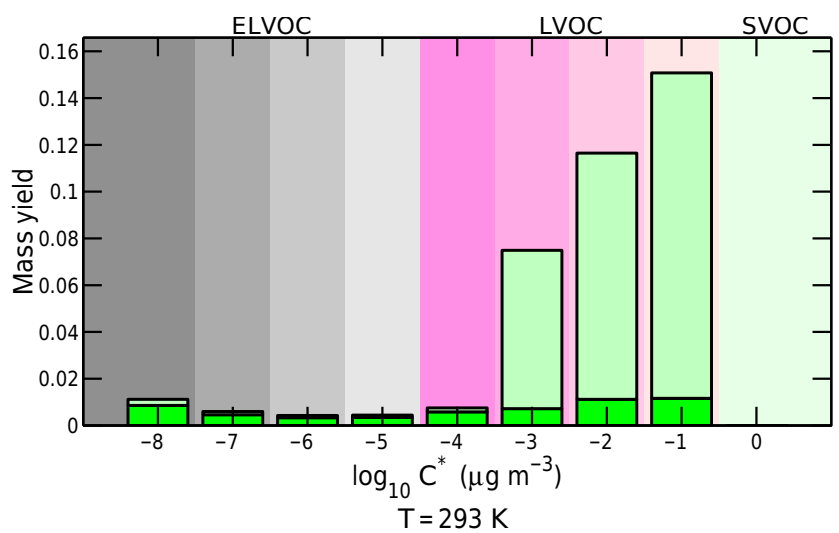

Figure 2. Distribution of highly oxidized multifunctional organic molecules from $\alpha$-pinene + ozone. Mass yields are consistent with product and growth-rate observations from CLOUD, but adjusted to $293 \mathrm{~K}$ consistent with typical secondary organic aerosol chamber experiments. The dark green bars are the raw mass yields detected by the nitrate CIMS. The light green bars show additional mass required to reproduce CLOUD growth rates, assuming that the nitrate clustering efficiency in the CIMS declines with increasing product volatility.

cle growth rates for two different experimental conditions in CLOUD, as discussed in Tröstl et al. (2016).

Our base-case product volatility distribution does not conserve carbon. The total mass yields are roughly 0.38 and the corresponding molar carbon yields are 0.23 , so the distribution explains roughly one quarter of the ozonolysis products. The remaining products, with a molar yield of 0.77 , are too volatile to cause condensational growth under the CLOUD conditions. Those include SVOC products that may well condense in chamber experiments. There is compelling evidence that between 30 and $60 \%$ of the SOA from $\alpha$-pinene ozonolysis behaves like SVOCs, either evaporating during dilution (Grieshop et al., 2007; Vaden et al., 2011) or transferring between different suspended populations when they are mixed (Robinson et al., 2013; Ye et al., 2016b). However, our objective is to test whether the (E)LVOC products alone pose a mass balance problem for the chamber SOA experiments, and so in the following simulations we shall completely neglect any SVOC production, instead leaving any potential gaps between the (E)LVOC condensation and the total observed SOA to be explained by SVOCs.

\subsection{Polydispersity and the condensation sink diameter}

The condensation sink of vapors to particles is dependent on total available surface area, and thus the size and number concentration of the seed particles. As shown previously in Tröstl et al. (2016), the condensation flux (with units of micrograms per cubic meter per second, $\mu \mathrm{g} \mathrm{m}^{-3} \mathrm{~s}^{-1}$ ) is defined as follows: 


\section{Results and discussion}

$$
\begin{aligned}
& s_{i, \mathrm{p}}, \\
& \text { deposition rate of } \\
& \text { vapors at the surface } \\
& \Phi_{i, \mathrm{p}}^{\mathrm{v}, \mathrm{s}}=N_{\mathrm{p}} \underbrace{\left(\pi / 4\left(d_{\mathrm{p}}+d_{i}\right)^{2}\right)}_{\begin{array}{c}
\text { particle-vapor } \\
\text { collision cross section, } \\
\sigma_{\mathrm{v}, \mathrm{p}}
\end{array}} \overbrace{\alpha_{i, \mathrm{p}} v_{i, \mathrm{p}} B_{i, \mathrm{p}}} \underbrace{\left[C_{i}^{\mathrm{v}}-a_{i, \mathrm{p}}^{\prime} C_{i}^{\circ}\right.}_{\begin{array}{c}
\text { driving force of } \\
\text { condensation } \\
F_{i, \mathrm{p}}
\end{array}}]
\end{aligned}
$$

where $N_{\mathrm{p}}$ is the particle number concentration of a specific particle type (size or composition), $d_{\mathrm{p}}$ is the particle diameter, $d_{i}$ is the effective spherical diameter of molecule $i$ in the vapor phase, $\alpha_{i, \mathrm{p}}$ is the accommodation coefficient, $v_{i, \mathrm{p}}$ is the velocity, $B_{i, \mathrm{p}}$ is the Fuchs correction factor from the kinetic regime, $C_{i}^{\mathrm{v}}$ is the vapor concentration, $a_{i, \mathrm{p}}^{\prime}$ is the activity of the organics in the particle phase, and $C_{i}^{\circ}$ is the saturation vapor concentration over a pure, flat, sub-cooled liquid surface. The total condensation flux is the sum over all particle sizes and types: $\Phi_{i}^{\mathrm{v}, \mathrm{s}}=\sum_{\mathrm{p}} \Phi_{i, \mathrm{p}}^{\mathrm{v}, \mathrm{s}}$.

Particles in chamber studies are rarely monodisperse; they often vary in size by up to an order of magnitude. When simulating the condensed-phase composition, it is computationally more efficient and conceptually more straightforward to consider a monodisperse distribution. A polydisperse model can be approximated by a monodisperse model using a condensation sink-weighted average diameter to represent the total particle population with the appropriate vapor-particle equilibration timescales. The condensation sink diameter is the diameter that monodisperse particles would have to have in order to preserve the condensation sink and the total number concentration of a polydisperse population. This does not conserve the seed-particle mass (it roughly conserves surface area), so the seed mass concentrations in these simulations do not match observations. We determine the condensation-sink diameter by summing the contribution to the condensation sink from each size bin, and calculating the diameter of a monodisperse seed that would produce the same condensation sink. In other words, we find a monodisperse seed of size $d_{\mathrm{p}}^{\mathrm{CS}}$ such that the following applies:

$k_{\mathrm{c}}\left(d_{\mathrm{p}}^{\mathrm{CS}}, \sum_{j}^{n} N_{\mathrm{p}, j}\right)=\sum_{j}^{n} k_{\mathrm{c}, j}\left(d_{\mathrm{p}}, N_{\mathrm{p}}\right)$,

where

$k_{\mathrm{c}}\left(d_{\mathrm{p}}, N_{\mathrm{p}}\right)=N_{\mathrm{p}}\left(\pi / 4\left(d_{\mathrm{p}}+d_{i}\right)^{2}\right) \alpha_{i, \mathrm{p}} v_{i, \mathrm{p}} B_{i, \mathrm{p}}$.

In the following simulations we compare simplified cases with a monodisperse seed population set initially at the seed condensation sink diameter with a polydisperse simulation in which we initialize the simulation using the seed size distribution spread over 108 distinct particle sizes, and then allow the diameter of each seed bin to evolve as net condensation dictates.

\subsection{Modeling organic aerosol production}

In Fig. 3 we show simulations of the two CMU experiments. In Experiment 1 the $\alpha$-pinene oxidation produces a total of about $36 \mu \mathrm{g} \mathrm{m}^{-3}$ of (E)LVOC products, while in Experiment 2 the oxidation produces about $81 \mu \mathrm{g} \mathrm{m}{ }^{-3}$ of (E)LVOC products. Because the products are effectively nonvolatile and the seed concentrations were similar, aside from the different scales on the $y$ axes, the simulations look very similar. Figure $3 \mathrm{a}$ and $\mathrm{c}$ are results from the monodisperse model using the weighted condensation-sink diameter, and Fig. 3b and $\mathrm{d}$ are the polydisperse model results. The different colors denote different reservoirs of organics. The light blue is the concentration of organics that have not yet been formed by ozonolysis - essentially a proxy for the remaining $\alpha$-pinene. The grey, which will be shown more prominently later, is the oxidized products that are in the vapor phase, $C^{\mathrm{v}}-$ these are products that have yet to condense. The red is vapors that have been absorbed into the Teflon walls of the chamber, $C^{\mathrm{t}}$. The dark blue is organics condensed onto particles that subsequently were deposited to the chamber walls, $C^{\mathrm{d}}$. The green is organics that have condensed but remain suspended in the bulk of the chamber, $C^{\mathrm{s}}$.

There is very little difference between the monodisperse (condensation sink diameter) and polydisperse models, which is immediately evident upon inspection of Fig. 3. Furthermore, the large majority of the condensible mass condenses onto suspended particles that are then lost to the chamber walls (the green and blue swaths). On this scale condensible vapors still in the gas phase (gray) appear to play a minor role. Relatively little mass (the red swath) condenses directly to the chamber walls, and so a back extrapolation of the suspended particle mass to $t=0$ would result in a reasonably accurate estimation of the total SOA mass yield at the end of the experiment.

In Fig. 4 we compare the chamber aerosol mass data and the model results for both the suspended seed mass concentration and the suspended organic aerosol mass concentration over the duration of each experiment. Here the organic aerosol is shown in green and the ammonium-sulfate seed mass in hashed red. In both cases, the model substantially overpredicts the observed organic mass concentrations at all times, but the mismatch is significantly greater for Experiment 1, which also had less than half the total aerosol mass loading. Because the model treats only (E)LVOC formation and omits any SVOCs, this strongly suggests that there is a discrepancy between the mass yields required to explain particle growth rates in CLOUD and the mass yields observed at much higher concentrations in smog-chamber studies. Delayed condensation and wall losses of (E)LVOC vapors are likely not a sufficient explanation for the disagreement, as both are treated in the model. However, the larger discrepancy at lower mass loading is an example of the type of data 
(a)

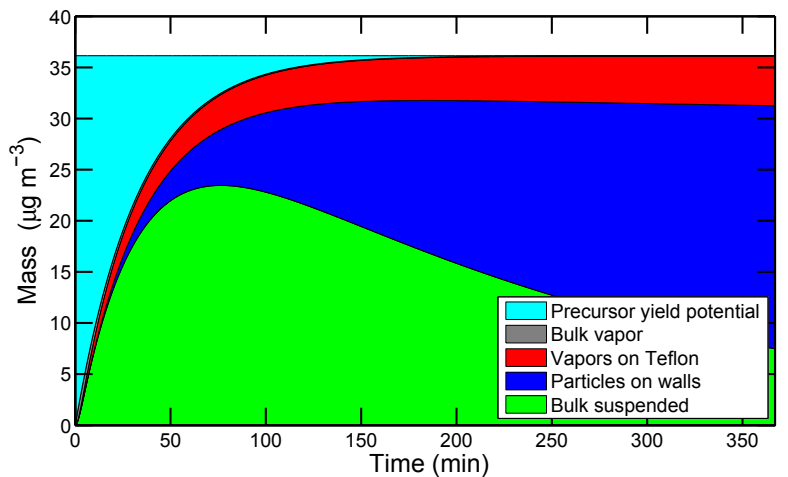

(c)

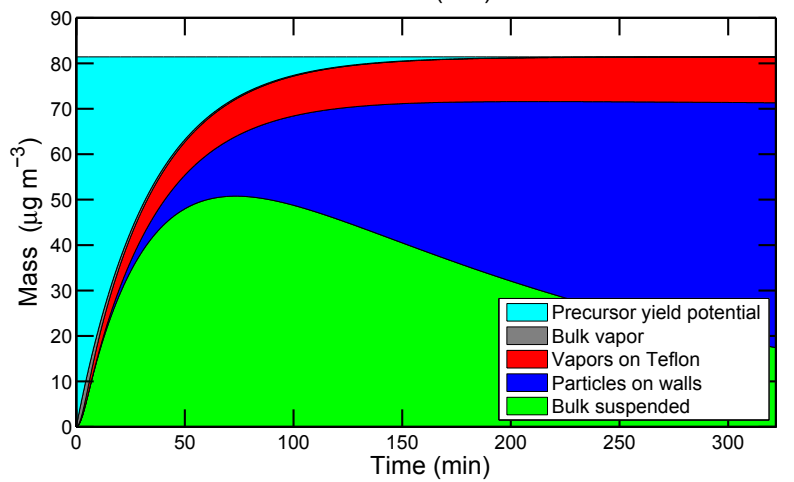

(b)

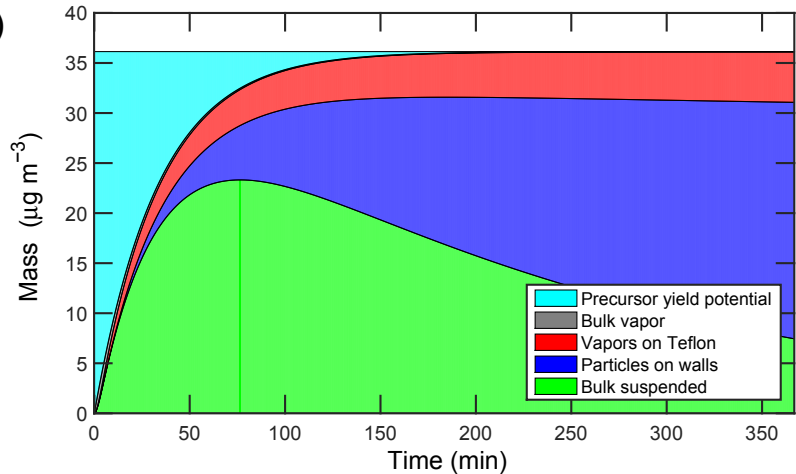

(d)

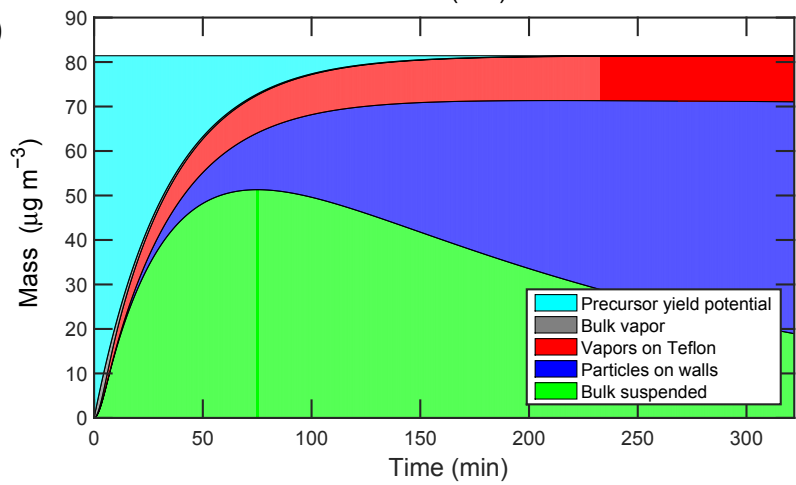

Figure 3. Dynamic simulation of $\alpha$-pinene SOA for two experimental conditions, using a monodisperse and polydisperse model. The simulations describe five different reservoirs: potential product from unreacted $\alpha$-pinene, vapors, suspended particles, deposited particles, and sorption to teflon, as shown in the legend. Panels (a) and (b) are the monodisperse and polydisperse results for Experiment 1, respectively. Panels (c) and (d) are the monodisperse and polydisperse results for Experiment 2, respectively. The monodisperse model uses a "condensation sink diameter" to approximate the rate that organics condense onto particles. This serves as a good proxy for a polydisperse model that accounts for the different condensation sinks for a polydisperse seed distribution.

(a)

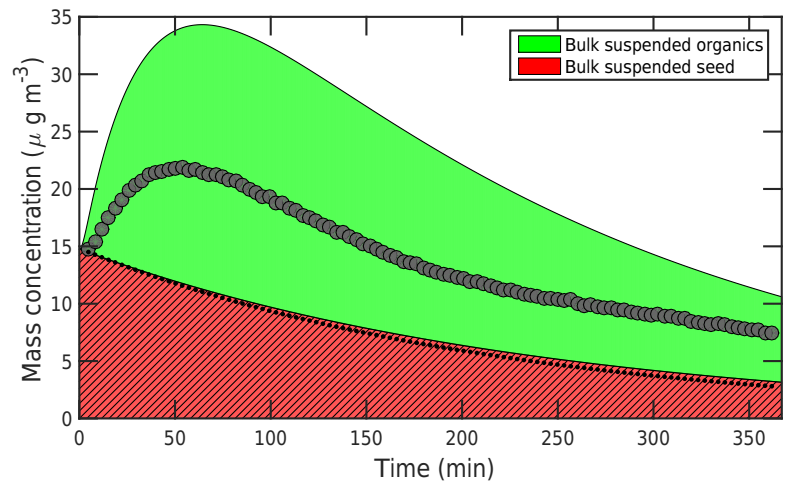

(b)

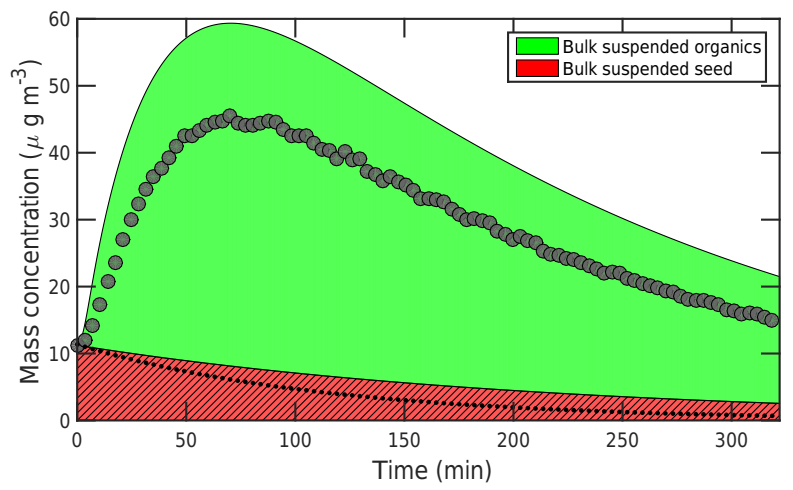

Figure 4. Comparison of the CLOUD-constrained VBS model and the CMU chamber experiments for $\alpha$-pinene ozonolysis. For both Experiment 1 (a) and Experiment 2 (b) the data (symbols) lie well below the model results of seed mass and organic mass over the full course of the experiment. This may be due to different experimental conditions, primarily the higher rate of ozonolysis in the SOA experiments.

that inspired the Odum et al. (1996) interpretation; observed SOA mass yields tend to be lower at lower mass loading, and the reference point here is an essentially nonvolatile suite of (E)LVOCs.

In Fig. 5 we show the Odum plots - the mass yield of SOA versus the total organic mass produced - for both simula- tions. In this case we assume that all deposited particle mass is accounted for, and so with the solid green curve we plot the total SOA concentration at any given time: $C_{\mathrm{OA}}=C^{\mathrm{s}}+C^{\mathrm{d}}$. However, the mass yield is given by $C_{\mathrm{OA}} / \Delta \alpha$-pinene and so excludes any vapors yet to condense as well as any vapors lost to the teflon walls. With the dashed curve we show the 
(a)

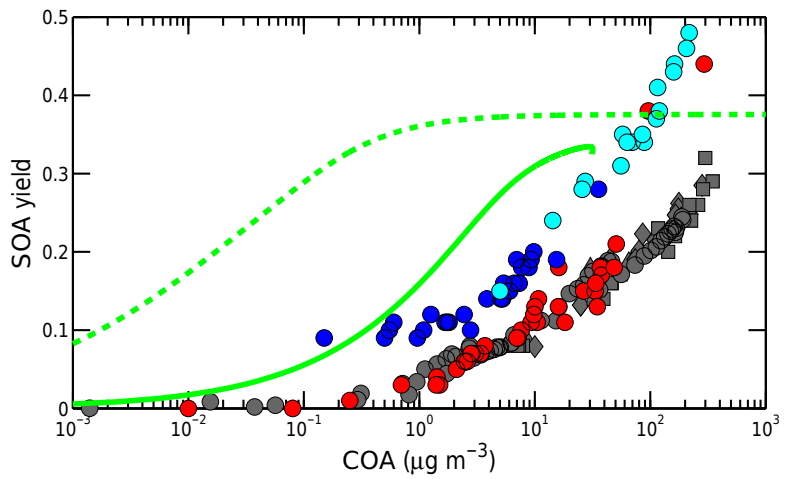

(b)

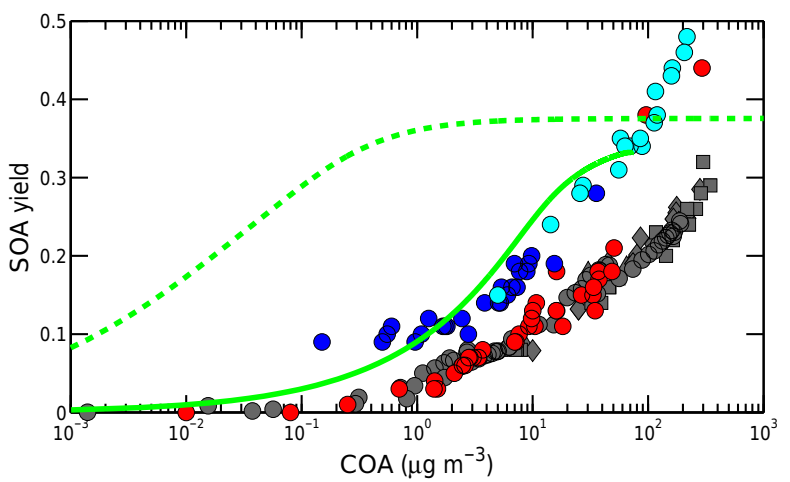

Figure 5. Odum plots from model runs of the experiments. Model results for Experiment 1 (a) and Experiment 2 (b) as solid green curves, compared to prior data from Presto and Donahue (2006) in grey, Shilling et al. (2008) in blue, Pathak et al. (2007a) in red, and Song et al. (2007) in cyan. The Odum plots show the model predicting higher yields than prior experiments. The dotted green curve is the equilibrium partitioning yield at a certain total organic aerosol mass. The model demonstrates that there is a significant time delay to condensation, as the solid line is far below the equilibrium line. Thus, it is possible to have substantial production of low-volatility products from $\alpha$-pinene ozonolysis that results in the experimental data shown in this plot.

equilibrium partitioning, which is the expected mass yield if the system were to reach instantaneous equilibrium without any vapor wall losses, as depicted in Fig. 1. Even though there is little evident vapor in Fig. 3, here we see that there is a dramatic difference between the dynamic and equilibrium cases. This is because the difference is confined to relatively small $C_{\mathrm{OA}}$ values early in the run, and they simply fail to register on the linear scale of Fig. 3. There is also a small difference in the asymptotic values of the dynamic and equilibrium models because of the vapor wall losses, but this is less significant than the dynamic delay of condensation.

We plot various SOA mass yields presented in the literature in Fig. 5. In red we plot the time-dependent mass yields from Pathak et al. (2007a), including Experiments 1 and 2. The red data and green model curves are thus directly comparable. The solid green dynamic simulation and the red data points disagree, consistent with the overshoot also evident in Fig. 4. In gray we show yields discussed in Presto and Donahue (2006), which include chamber results from Odum et al. (1996), Griffin et al. (1999), and Cocker et al. (2001). Those data agree well with the cases we are modeling here.

In Fig. 5 we also show SOA mass yields from Shilling et al. (2008) and Song et al. (2007), which are significantly higher than Pathak et al. (2007a) and Presto and Donahue (2006). These experiments agree reasonably well with the current simulations, though for most of the data from Shilling et al. (2008) the chamber was operated in a CSTR mode, and our simulations are for a batch mode, so the comparison should be made with care. A CSTR, or continuous flow stirred-tank reactor, has a constant flow of reactants into the chamber and product mixture out of the chamber, while a batch reactor does not. However, the different mass yields reported by Shilling et al. (2008), and Song et al. (2007) raise the possibility that different experimental conditions in different chamber studies might partially explain the apparent discrepancy between mass yield and growth-rate observations.

The difference between the dynamic and equilibrium simulations evident in Fig. 5 shows that one cannot necessarily assume equilibrium partitioning when determining SOA mass yields. The model demonstrates that when smog chambers are not treated dynamically, it is possible to miss substantial yields of low-volatility organic compounds that are effectively held up in the gas phase before condensing. However, the simulations still predict substantially more SOA at any given $C_{\mathrm{OA}}$ than we have reported previously, so this delay does not by itself resolve the apparent discrepancy.

Part of the dynamic effect is the delay between the production and condensation of (E)LVOCs. We show this delay more clearly in Fig. 6a by focusing on the first few minutes of Experiment 1, shown in Fig. 3a. As the experiment starts, the amount of oxidized $\alpha$-pinene increases nearly linearly, but the bulk vapor concentration (grey) grows substantially before condensation to the bulk suspended particles begins to be significant. In addition, this reservoir remains as the experiment progresses because there is always a steady-state concentration of condensible vapors driving particle growth, indicating that the delay occurs throughout the experiment and emphasizing the importance of having a dynamic model. In Fig. 6b we show the fractional product distribution for this same experiment over the first $90 \mathrm{~min}$ of the experiment by normalizing each product reservoir by the total concentration of condensible products, $C^{\text {tot }}=C^{\mathrm{v}}+C^{\mathrm{t}}+C^{\mathrm{d}}+C^{\mathrm{s}}$. This confirms that the dynamic effect is greatest early in the experiment but also that a combination of steady-state condensation delay and vapor wall losses contribute at all times. For this simulation the suspended condensation sink timescale was a few minutes, and so the dynamic effect of the uncondensed 
(a)

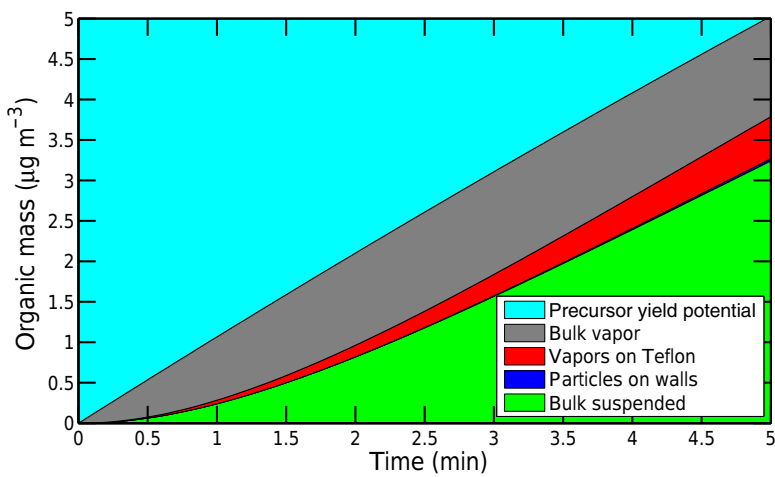

(b)

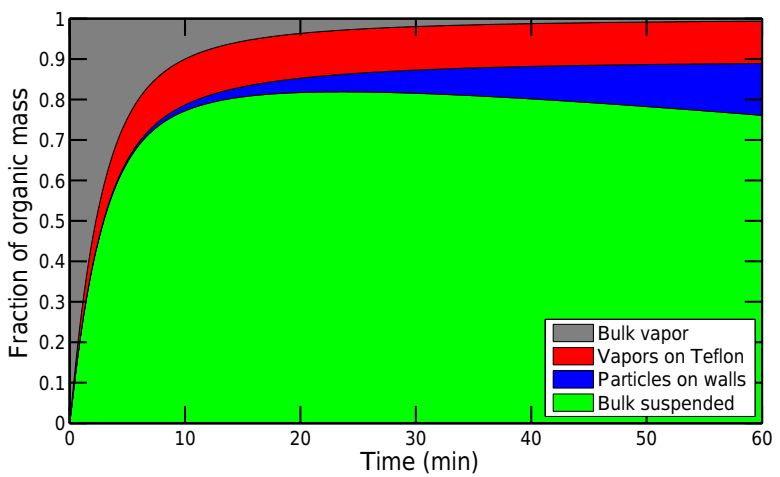

Figure 6. Mass distribution among organic reservoirs. The first 5 min of Experiment 1 (a) show the different reservoirs of organic mass, including a substantial fraction of uncondensed vapors (gray). The buildup of the bulk vapors demonstrates that there is a significant delay between the formation of low-volatility compounds and the condensation of these compounds onto particles. This results in lower detected yields during chamber experiments and the loss of vapors to the walls. The fraction of organics in each of the reservoirs over the first 90 min is shown in (b). At the beginning, all of the organics are in the bulk vapor reservoir. The bulk vapor fraction decreases as vapors condense or are lost to the walls and claim a larger fraction of total organic mass.

vapors almost completely vanishes after $20 \mathrm{~min}$, consistent with the expected equilibration timescale (Saleh et al., 2013).

Another potential explanation for the difference between CLOUD (E)LVOC yields and smog-chamber experiments is the different experimental conditions in the chambers. Specifically, the CMU experiments have reaction rates almost 3 orders of magnitude higher than the CLOUD experiments $\left(19 \mathrm{pptv} \mathrm{s}^{-1}\right.$ versus $\left.0.03 \mathrm{pptv} \mathrm{s}^{-1}\right)$. As reaction rates increase, the higher frequency of collisions of intermediate products with each other may terminate the autooxidation reactions that create the HOMs, producing higher volatility yields than those seen at CLOUD. This may be especially important for termination reactions between peroxy radicals $\left(\mathrm{RO}_{2}\right)$, which are second order and will increase in importance for higher overall reaction rates. While we can not rule this out as a cause of the apparent discrepancy, we do not yet have sufficient data for the smog-chamber experiments to test whether the apparent yield of HOMs is lower under the highconcentration conditions of the SOA formation experiments than under the more atmospherically representative experiments conducted at CLOUD. Furthermore, the original Ehn et al. (2014) plant-chamber experiments were carried out under conditions much closer to traditional smog-chamber experiments and still revealed high (E)LVOC mass yields. Conducting SOA formation experiments at very low oxidation rates is not an obvious solution, as the resulting mismatch between ambient and chamber SOA concentrations and also the very small growth rates compared to the relatively large particle wall-loss rates would make data interpretation extremely difficult; the experiments have been carried out rapidly at ambient SOA concentrations for a reason.

We can also compare CLOUD and the CMU chamber via the presence or absence of nucleation. Specifically, the CLOUD experiment was designed to observe nucleation from $\alpha$-pinene ozonolysis (Kirkby et al., 2016), whereas no nucleation occurred in the experiments reported by Pathak et al. (2007a). However, the oxidation rate in Pathak et al. (2007a) was more than 2 orders of magnitude higher than that in Kirkby et al. (2016) yet the condensation sink was only about 1 order of magnitude higher, so the concentrations and thus saturation ratios of ELVOCs in the CMU chamber should have been higher than in CLOUD if the product yields were identical. Indeed, in Fig. 7a and b we show the simulated vapor supersaturation ratios from each volatility bin for Experiment 1 and Experiment 2, respectively, based on the (E)LVOC yields from Kirkby et al. (2016). The ELVOC saturation ratio reaches $10^{7}$ for the $C^{*}=10^{-8} \mu \mathrm{g} \mathrm{m}^{-3}$ ELVOCs; this is an order of magnitude higher than the saturation ratio in CLOUD (see extended data, Fig. 7 in Tröstl et al., 2016), confirming that nucleation should have occurred if the chemistry was identical in the two experiments.

To estimate the nucleation rates expected in the CMU experiments, we assume that new-particle formation is driven only by compounds in the $C^{*}=10^{-8} \mu \mathrm{g} \mathrm{m}^{-3}$ ELVOC bin, which comprises $\sim 10 \%$ of the total detected HOMs in the CLOUD experiments, almost exclusively as covalently bound $C_{20}$ dimers (see extended data, Fig. 5 in Tröstl et al., 2016). Figure 3 in Kirkby et al. (2016) relates the nucleation rate to the detected HOM concentration. The data in the $\log -\log$ plot have a slope of 2 , indicating that the nucleation rate is a second-order reaction with respect to the ELVOC concentration. Assuming that only the $C^{*}=$ $10^{-8} \mu \mathrm{g} \mathrm{m}^{-3}$ ELVOCs actually drive nucleation, we adjust the Kirkby et al. (2016) HOM concentrations down by a factor of 10 and so derive a nucleation rate constant of $k_{\text {nuc }} \simeq$ $4 \times 10^{-14} \mathrm{~cm}^{3} \mathrm{molec}^{-1} \mathrm{~s}^{-1}$. It is interesting to note that this is still only a small fraction of the collisional rate constant. Using the nucleation rate constant, we calculate the nucleation rate for each experiment from Pathak et al. (2007a), which we show in Fig. 7c and d. By integrating the nucle- 
(a)

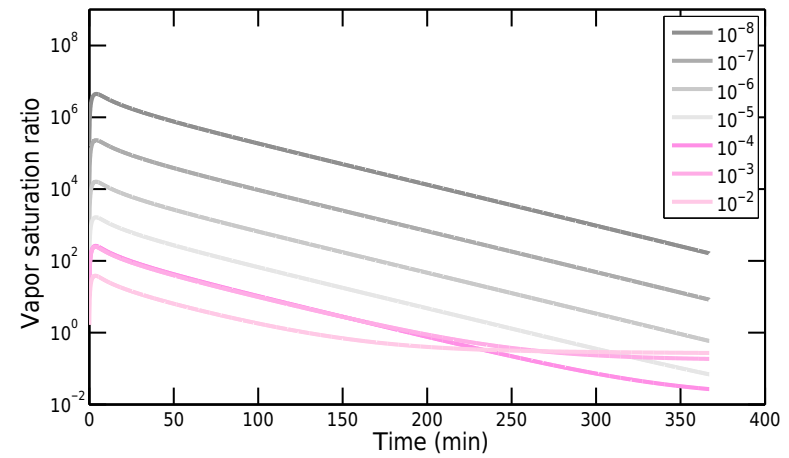

(c)

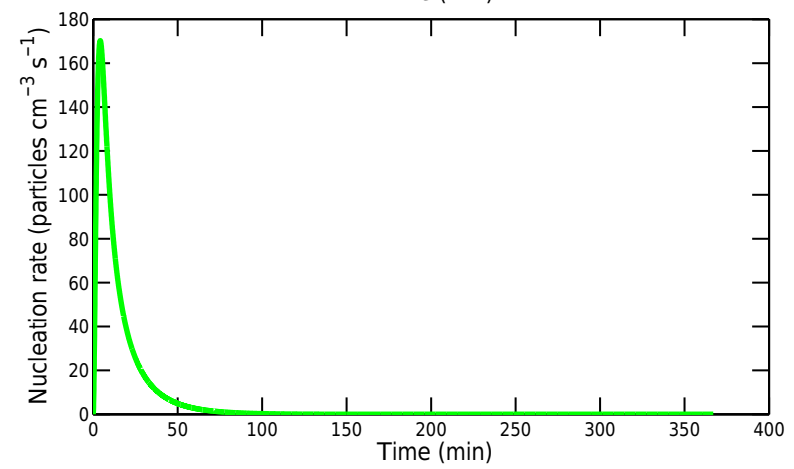

(b)

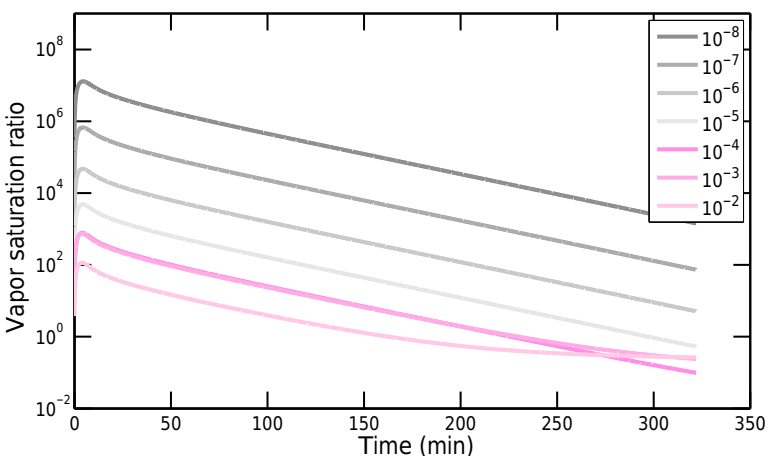

(d)

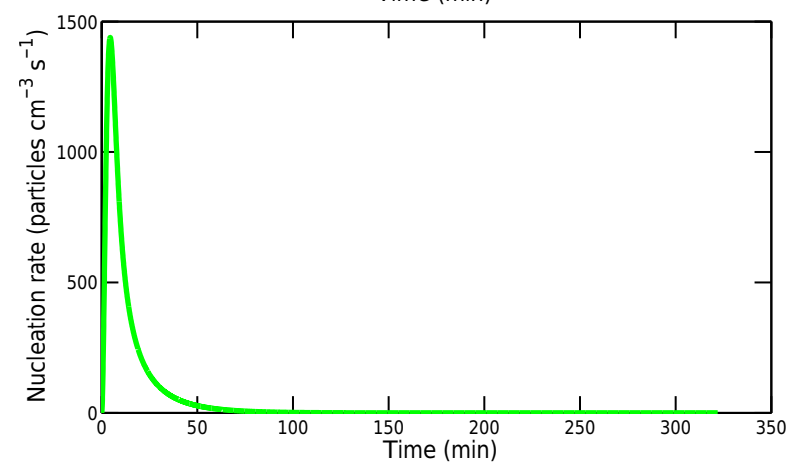

Figure 7. Vapor saturation ratios for smog-chamber experiments. Simulated vapor saturation ratios in the CMU smog chamber for Experiment 1 (a) and Experiment 2 (b). The color of the line indicates the volatility bin, with the ELVOCs in shades of grey and LVOCs in shades of pink, and darker shades indicate lower volatility within the category. The saturation ratio of the least volatile $\operatorname{ELVOC}\left(C^{*}=10^{-8} \mu \mathrm{g} \mathrm{m}^{-3}\right.$, dark grey) can be used to predict nucleation rates based on CLOUD data, which are shown in the lower panels for Experiment 1 (c) and Experiment 2 (d). However, no nucleation was observed during these experiments.

ation rate over time, we find that the concentration of nucleated particles that would have formed is on the order of $10^{5}$ to $10^{6} \mathrm{~cm}^{-3}$. These particles would have had growth rates of hundreds of nanometers $(\mathrm{nm})$ per hour, indicating fast growth into larger sizes that are easily detected in the SMPS. However, this was not observed. Consequently, we conclude that the experimental conditions employed by Pathak et al. (2007a) suppressed ELVOC (covalent dimer) formation relative to the conditions described by Kirkby et al. (2016). This is consistent with the hypothesis that the production of ELVOCs is interrupted under higher $\alpha$-pinene concentrations, possibly through the termination of $\mathrm{RO}_{2}$ autooxidation reactions.

\subsection{Oligomerization}

So far our analysis has followed the base-case model of Tröstl et al. (2016), which assumes that (E)LVOC condensation drives the CLOUD growth rates and so that the nitrate CIMS sensitivity to LVOCs was low (and thus their concentrations were high). As Tröstl et al. (2016) pointed out, an alternate explanation for their growth-rate observations is that SVOC condensation followed by oligomer formation could play a role. Oligomerization has been shown to be important to SOA formation (Kalberer et al., 2004; Tolocka et al., 2004;
Heaton et al., 2009) and consistent with SOA chamber mass yield observations (Trump and Donahue, 2014). Semivolatile organics in the condensed phase may interact with particlephase HOMs, creating an ELVOC product. This sequesters SVOC compounds that would otherwise easily evaporate off of a particle. Furthermore, because the growth rates observed in CLOUD are small and the time constants are long (many hours), it is possible that this slow chemistry might not be evident on the shorter timescales of the SOA formation chamber experiments we are modeling here.

As in our previous simulations, we start by creating a model that matches the growth-rate results from CLOUD. There is little information on the actual yield of semivolatile organics; thus we are merely looking to show that there is a reasonable hypothetical yield that can reproduce the CLOUD data. In this model, we start with the unscaled yields from CLOUD (the dark green in Fig. 2) and add in an SVOC mass yield of 0.20 in the $C^{*}=10^{1} \mu \mathrm{g} \mathrm{m}{ }^{-3}$ volatility bin. As a simple proof of concept we assume that this compound will react with any condensed-phase organic species to form an ELVOC product. As described by Trump and Donahue (2014), the rate of dimerization is given by

$$
R_{\text {dimer }}=C_{\mathrm{OA}}\left(k_{\mathrm{f}} w_{\mathrm{m}} w_{\mathrm{org}}-k_{\mathrm{r}} w_{\mathrm{d}}\right),
$$


(a)

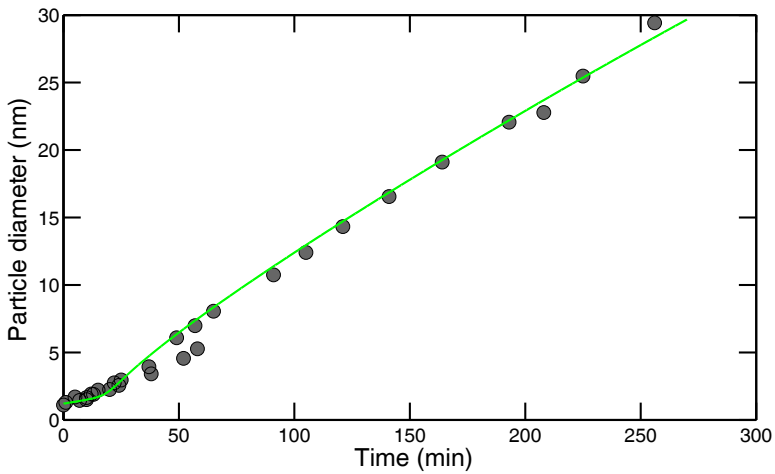

(c)

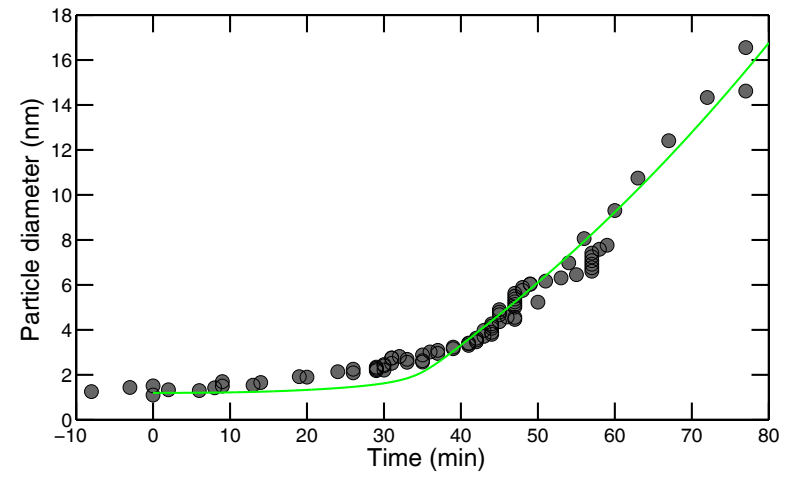

(b)

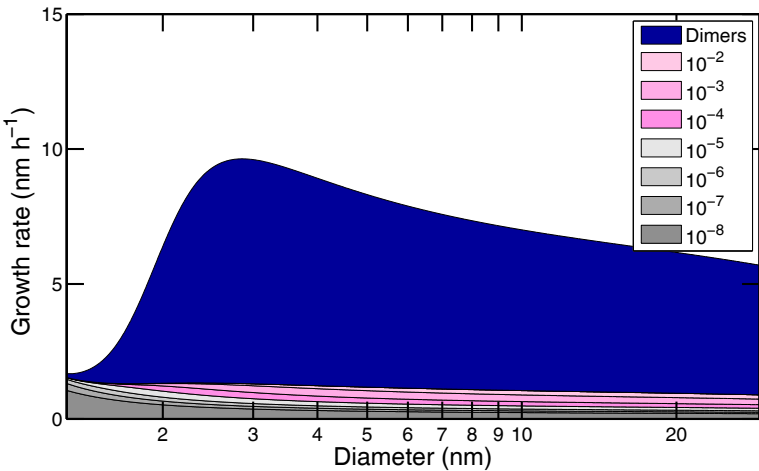

(d)

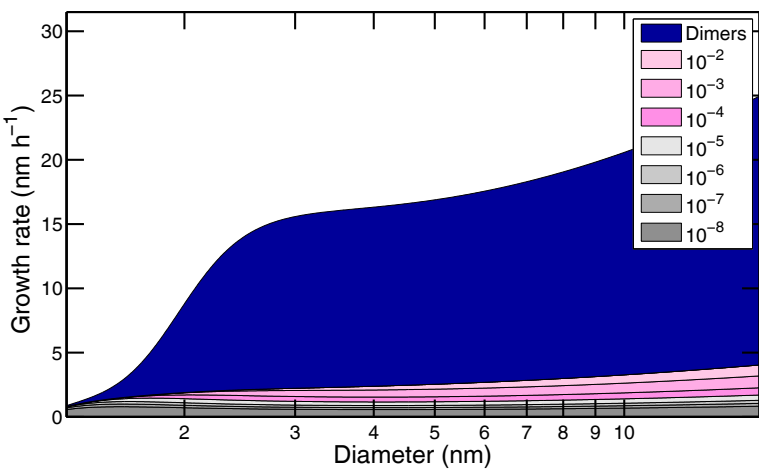

Figure 8. Oligomerization model results for CLOUD experiments. Oligomerization model particle diameters for the constant HOM (a) and rising HOM (c) CLOUD experiments, along with VBS bin contributions to growth rate versus diameter for the constant HOM (b) and rising HOM (d) CLOUD experiments. The dark blue is the contribution to growth from dimers. The acceleration near $2 \mathrm{~nm}$ is caused because SVOC monomers evaporate from smaller particles due to the Kelvin effect but react to form ELVOCs in larger particles.

where $C_{\mathrm{OA}}$ is the organic aerosol concentration, $k_{\mathrm{f}}$ is the forward rate constant of dimerization, $w_{\mathrm{m}}$ is the mass fraction of monomers, $w_{\text {org }}$ is the mass fraction of other organics in the particle phase (we assume the monomer reacts with all organics, so $\left.w_{\text {org }}=1\right), k_{\mathrm{r}}$ is the dissociation rate constant, and $w_{\mathrm{d}}$ is the mass fraction of dimers. For the purpose of this simple model, we assume that there is no dimer dissociation $\left(k_{\mathrm{r}}=0\right)$. The CLOUD chamber operated at low $\alpha$-pinene concentrations. Thus, when we use the original, lower yield distribution, the dimerization rate must be high in order to produce the detected growth rate; we find that $k_{\mathrm{f}}=2 \times 10^{4} \mathrm{~min}^{-1}$ reproduces the observations reasonably well.

Figure 8 shows the model results of the CLOUD experiments. Figure 8a and b show the results of the constant HOM experiment, and Fig. 8c and d show the increasing HOM experiment. Descriptions of these experiments are detailed in Tröstl et al. (2016). In both cases, the oligomerization model reproduces the particle size and growth rate over the course of the experiments. Figure $8 \mathrm{~b}$ and d show the contributions from each of the volatility bins to the growth rate. The colors indicate the volatility of the compound, as shown in Fig. 2, with the dimers shown as dark blue following Trump and Donahue (2014). The ELVOC and LVOC compounds contribute very little to the overall particle growth after the very early stages of growth, because for this simulation we assume that the nominal CIMS concentrations are accurate. Consequently, oligomerization of SVOCs must explain the (large) residual growth. Because of the high condensed-phase rate constant, nearly all of the SVOCs that condense are immediately converted to ELVOC dimers except for the very smallest particles; simulations including a slower forward reaction simply required much higher monomer yields, which we rejected as unrealistic. The SVOC monomer does evaporate from the smallest particles because of the Kelvin enhancement. If we model the oligomerization as effectively instantaneous, the growth rate for the smallest particles rises sharply. Thus the ratio of the monomer volatility to the forward rate constant is meaningful, along with the Kelvin diameter of the SVOCs (Tröstl et al., 2016), but the individual values are practically unconstrained. While the growth-rate plot differs somewhat from the model constrained entirely by (E)LVOCs (Tröstl et al., 2016), the experimentally determined growth rate at $10 \mathrm{~nm}$ matches the model. Therefore, for the purposes of this exercise, this is a second product model consistent with the CLOUD observations.

We can now take this oligomerization model and apply it to the SOA formation experiments from the CMU chamber. In Fig. 9 we compare the base case (high LVOC) simulation with the oligomerization simulation, with the oligomer- 
(a)

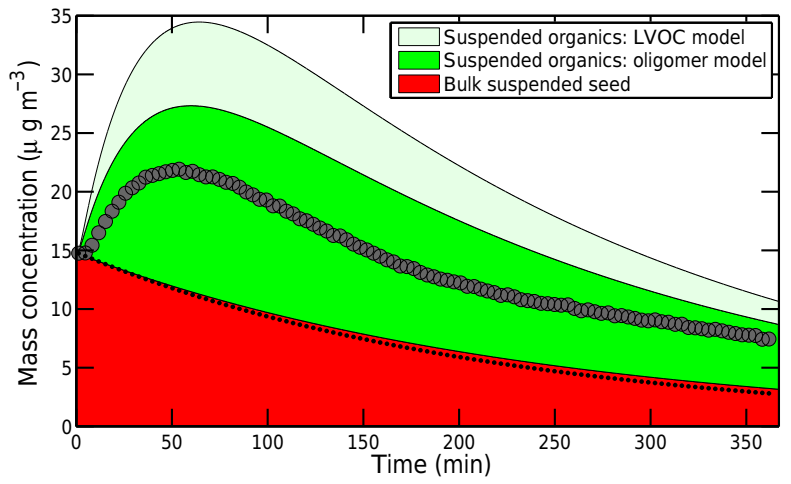

(b)

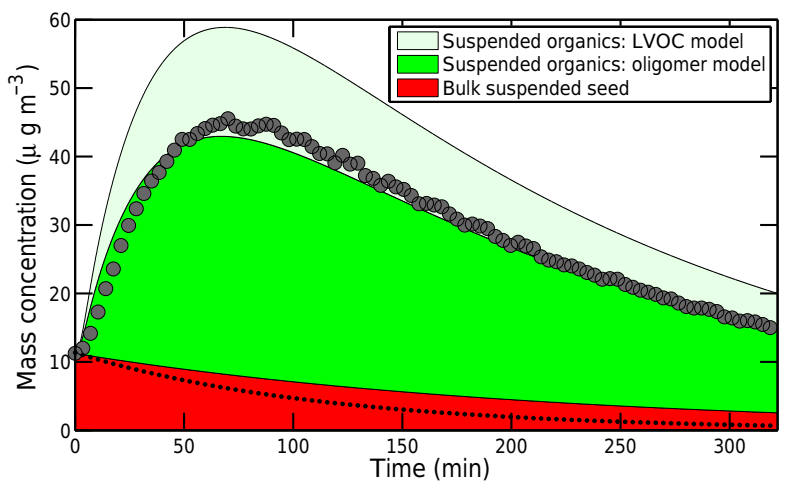

Figure 9. Comparison of organic mass produced between an oligomerization model and the CMU chamber experiments. Model results and data for organic (green) and seed mass (red) over time for Experiment 1 (a) and Experiment 2 (b). Solid green is the oligomerization model while the light green shows the (additional) mass from the base-case (high LVOC) model. The oligomer model overpredicts Experiment 1 , though not as much as the base-case model, and reasonably matches Experiment 2.

ization case represented in dark green and the (extra mass from the) (E)LVOC simulation shown in light green. The oligomerization model results in a better fit to the data, though for Experiment 1 the model continues to overpredict the observations. In Fig. 10 we show an Odum plot for Experiment 2, reproducing Fig. 5b but now also including this oligomerization simulation. There is relatively little difference between the base-case high LVOC simulation and the oligomerization simulation at low $C_{\mathrm{OA}}$, early in the experiment, and here the model continues to overshoot the observations. This is also apparent in Fig. 9b. However, for the bulk of the simulation with $C_{\mathrm{OA}}>1 \mu \mathrm{g} \mathrm{m}^{-3}$, the oligomerization simulation falls considerably closer to the data, and within the range of literature data.

In the oligomerization simulation, to reproduce the particle growth rates without excessive monomer concentrations we had to assume nearly irreversible condensation of monomers and rapid oligomerization. The volatility of the SVOC monomer is only sufficient for evaporation to exceed reactive uptake at very small particle sizes $\left(d_{\mathrm{p}} \lesssim 2.5 \mathrm{~nm}\right)$, where the Kelvin effect enhances the saturation concentration sufficiently for evaporation to slow the growth. So far we have not found conditions with reversible oligomerization or slower oligomer formation that can reproduce the CLOUD growth-rate observations, though the phase space is vast. On its face, the rapid oligomerization case is not qualitatively very different from effectively nonvolatile condensation, though it does reproduce the slow growth rate at very low particle diameters observed in the CLOUD experiment. It is thus somewhat surprising that the mass yields in the oligomerization simulations are significantly lower than the (E)LVOC case. Most of this difference is because a flux balance differs from a mass balance. The SVOC monomers are relatively light, with $M_{i}=175 \mathrm{~g} \mathrm{~mole}^{-1}$ compared to (E)LVOCs with $M_{i} \simeq 350 \mathrm{~g} \mathrm{~mole}^{-1}$. This means that for the same vapor mass concentration, the SVOC monomers have

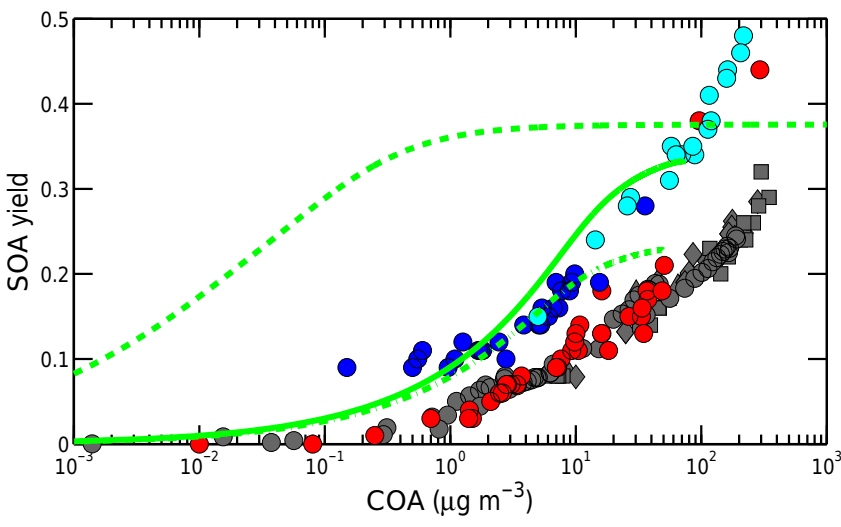

Figure 10. Odum plot with the LVOC and oligomer models for Experiment 2. The LVOC model is a solid green curve and the oligomer model is a dot-dashed green curve. The dashed green curve is the equilibrium partitioning yield. The data from Pathak et al. (2007a) (red circles) are directly comparable. Other literature data are from Presto and Donahue (2006) (grey), Shilling et al. (2008) (blue), and Song et al. (2007) (cyan). The oligomer model is consistent with some prior experiments.

a $44 \%$ higher condensation rate, simply because they have a higher velocity.

\subsection{The condensation sink and reaction rates}

At this point we have a dynamic model that can reproduce the growth-rate observations from CLOUD while not grossly overpredicting the SOA mass production rate observed in at least some SOA formation chamber experiments. However, the model still leaves no room for true SVOC condensation (save for nearly irreversible conversion to oligomers), and so it is not yet fully consistent with observations, strongly suggesting that $30-60 \%$ of the SOA in chambers is semivolatile. We thus can not rule out possible changes to the gas-phase 
(a)

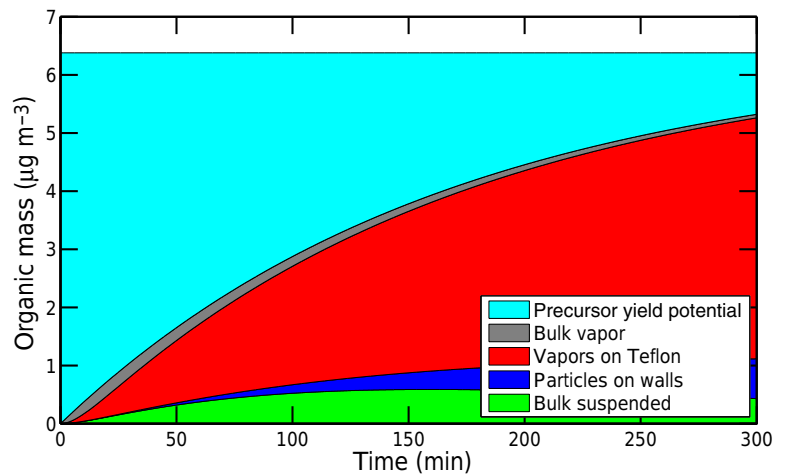

(c)

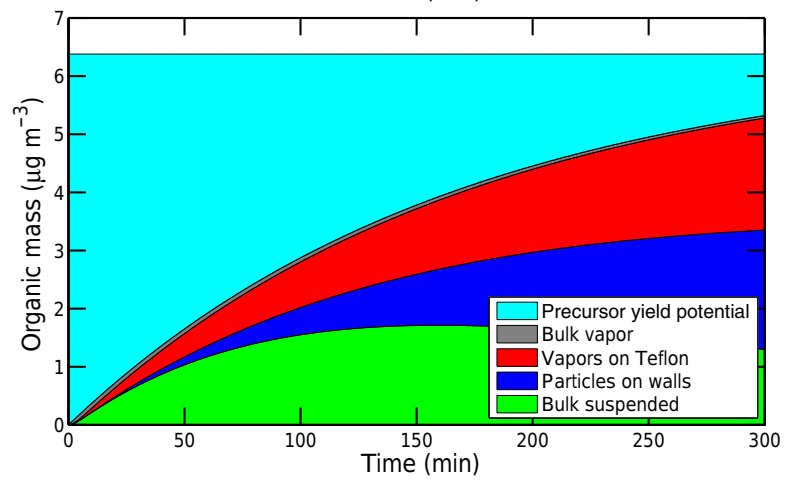

(b)

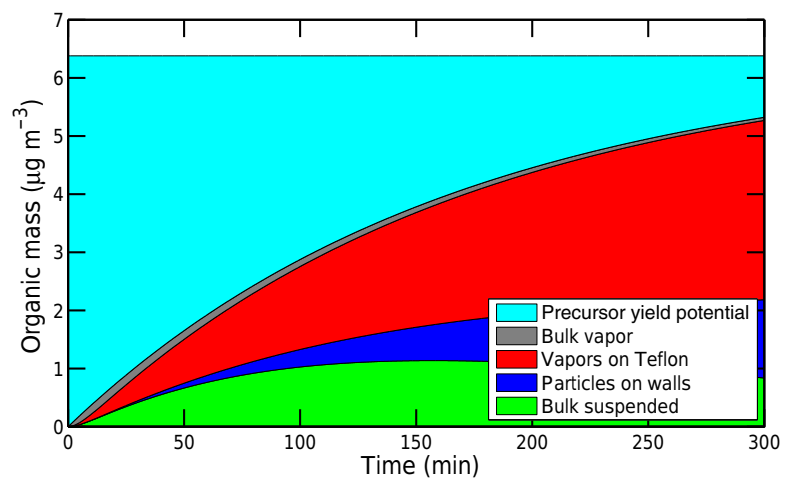

(d)

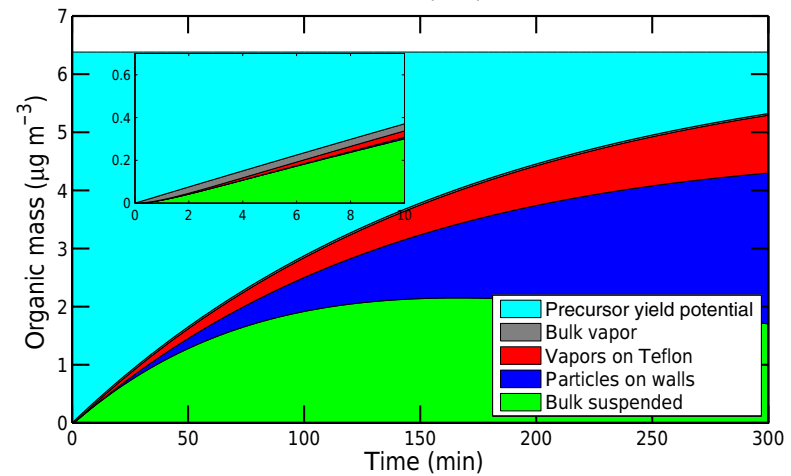

Figure 11. The effect of varying the particle-to-wall condensation sink ratio by varying the number of seeds at $3 \mathrm{ppb} \alpha$-pinene and $50 \mathrm{ppb}$ ozone. The CS ratio is the ratio of the suspended condensation sink to the vapor wall-loss rate constant. CS ratio $=0.3$ (a); $\mathrm{CS}$ ratio $=1$ (b); $\mathrm{CS}$ ratio $=3(\mathbf{c}) ; \mathrm{CS}$ ratio $=10(\mathbf{d})$. The key area is the grey area denoting the bulk vapor (the sliver between the teal and red), which comes from reacted products that have not yet condensed into the particle phase. For a CS ratio of 10, there is sufficient seed concentration to condense most of the vapors into the particle phase (mass of particles on walls and bulk suspended). Conversely, for a CS ratio of 0.3 , the lack of seeds causes a buildup of bulk vapor, most of which is then lost to the walls.

chemistry (and the volatility distribution of the products); this is difficult without corresponding measurements of gasphase HOMs via nitrate-CIMS in the chamber experiments. Indeed, our simulations of nucleation in the CMU experiments, and the absence of nucleation in the data, strongly suggest that at the very least the ELVOC yields were lower in the CMU experiments than in the CLOUD experiments.

Other dynamic effects also remain possible explanations, though they require future experiments to constrain. Coagulation and ion recombination affect growth rates, although their effects are strongest at smaller sizes $(<3 \mathrm{~nm}$; Lehtipalo et al., 2016). At the larger $(>10 \mathrm{~nm})$ sizes that we focus on, the growth rate should predominately be driven by condensation. Another possibility is that the mass accommodation coefficients differ in the high-mass SOA formation experiments and in the low-mass CLOUD experiments. However, the flux-balance constraints for CLOUD strongly suggest a mass accommodation coefficient near unity. Specifically, the total mass yields required to explain the growth rates already stretch plausibility, and $\alpha<1$ would only require higher vapor concentrations (and thus higher yields) to compensate for the lower specific condensation rate. However, if larger particles had a lower effective mass accommodation coefficient (for example driven by slow particle-phase diffusion), that might direct more vapors to the walls and lower the overall observed SOA production. We explore this by varying the particle condensation sink in our simulations, using the high LVOC simulations as our base case.

The particle condensation sink is key to condensing organic vapors, and in chamber studies, this condensation to suspended particles is in competition with the loss of vapors to chamber walls. The key to capturing oxidation products is therefore increasing the condensation sink by having a higher seed surface area. In general our design objective is to have a suspended seed condensation sink at least 10 times greater than the vapor-wall collision frequency. For the CMU chambers, with a vapor wall-loss frequency of approximately $0.1 \mathrm{~min}^{-1}$ (Ye et al., 2016a), this means that the ideal seed condensation sink is on the order of $1 \mathrm{~min}^{-1}$. The critical parameter is the ratio of the seed condensation sink to the wall-loss rate constant.

Figure 11 shows the locations of vapors given an initial particle-to-wall condensation sink ratio for a hypothetical mix of $3 \mathrm{ppb} \alpha$-pinene and $50 \mathrm{ppb}$ ozone. The CS ratio describes how likely an organic vapor molecule is to hit (and condense to) a particle versus the wall, and in broad terms for 
(a)

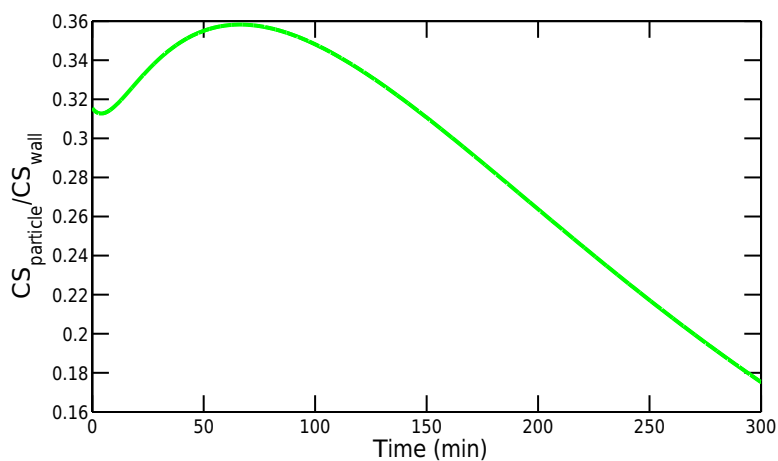

(c)

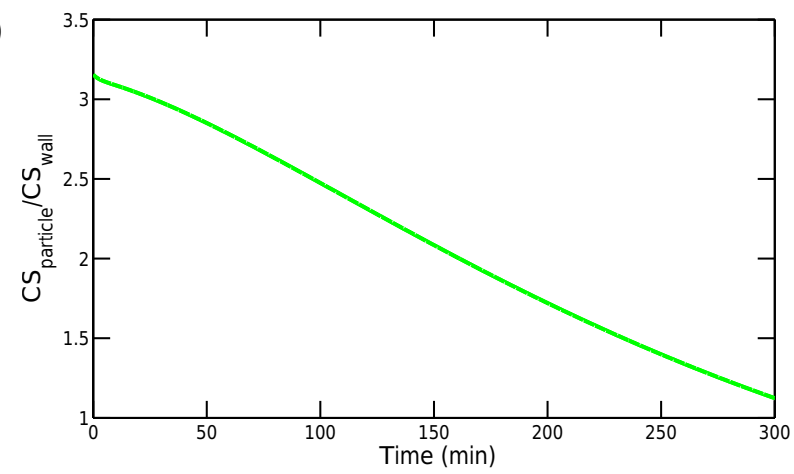

(b)

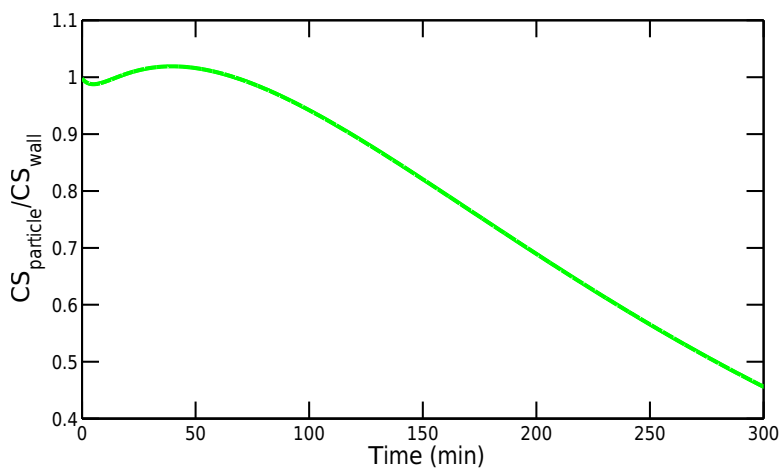

(d)

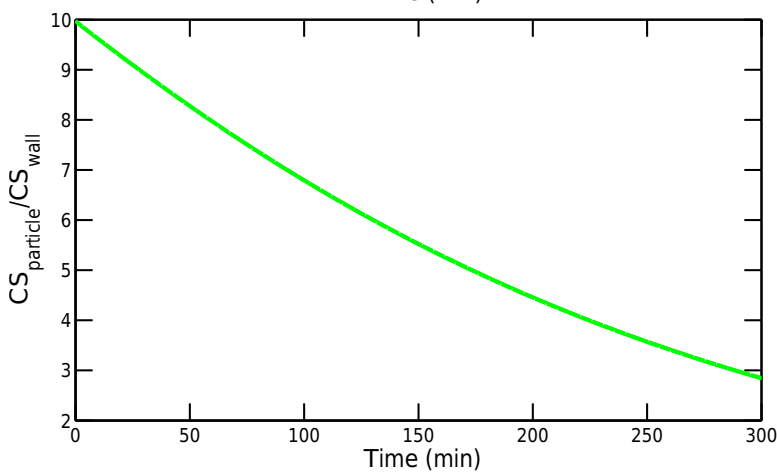

Figure 12. Evolving condensation sink (CS) ratio over the course of a chamber run, depending on the initial CS ratio. Each run has the same

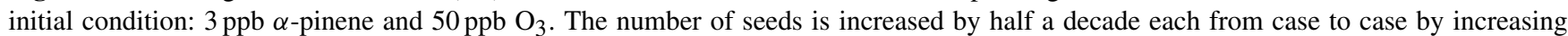
the particle number concentration. CS ratio $=0.3(\mathbf{a}) ; \mathrm{CS}$ ratio $=1$ (b); CS ratio $=3$ (c); CS ratio $=10$ (d). At a low CS ratio, fewer seeds mean that each seed grows substantially from condensation. Because the CS depends on the surface area of each particle, a faster growth of the surface area results in an increase in the particle condensation sink. At high seed concentrations, the initial rise in the CS ratio does not occur because each seed receives little organic mass. However, CS is also dependent on the particle number concentration. Therefore, the CS ratio steadily drops over the course of a chamber run as particles themselves are lost to the walls. The specific value of CS ratio at which the growth rate effect disappears is dependent on the amount of precursors and the oxidation rate of precursors.

this simulation where the condensible vapors are effectively nonvolatile, the CS ratio also gives the ratio of the condensation flux to the particles (the sum of the green and blue in Fig. 11) and the wall loss (the red in Fig. 11). For low CS ratios the condensible vapors build up (the gray in Fig. 11a), showing a delay of condensation of vapors to particles. The majority of these vapors are thus lost to the walls. Even in Fig. $11 \mathrm{~b}$, where the initial CS ratio is $1: 1$, more of the mass is lost to the walls than is condensed onto particles, though the ratio is close to $1: 1$. The slightly higher vapor wall loss is due to particle wall loss, which decreases the available surface area in the bulk chamber. As CS ratio increases, the bulk vapor concentrations decrease as higher particle condensation rates collect most of the organic mass.

The CS ratio is dependent on the total suspended surface area and thus both the particle number concentration and the particle diameters. Over the course of an experiment, there are competing processes that affect the CS ratio through these two variables. The particle number concentration decreases due to particle wall loss. The particle diameter increases due to condensation. However, the rate at which the diameter increases is also dependent on the particle number. In Fig. 12 we show the evolution of the CS ratio over time for the four CS-ratio simulations. At low CS ratios (Fig. 12a), or low particle concentrations, condensation has a greater effect on the diameter of each particle. This causes the $\mathrm{CS}$ ratio to increase initially before decreasing later from particle wall loss. For simulations with a higher initial CS ratio, the effect of particle diameter is lessened as the growth rate of each individual particle is slower. By the simulation shown in Fig. 12d, the diameter growth effect is negligible.

In addition to the CS ratio, the condensation rate is affected by the reaction rate. The reaction rate is simply the product of the reaction rate constant, the $\alpha$-pinene concentration, and the ozone concentration. With more rapid oxidation more condensation occurs early, before substantial particle wall losses deplete the condensation sink. Furthermore, the steady-state saturation ratios will be correspondingly higher. Figure 13a and $\mathrm{b}$ show the reservoirs of organic products at 500 and $5000 \mathrm{ppb}$ ozone, respectively. Compared to Fig. 11b, which has the same $\alpha$-pinene and seed concentrations, here organic aerosol mass is formed faster and concentrations are higher. Even though the LVOCs have very low volatility, we can also see evaporation of organics off the particles toward 
(a)

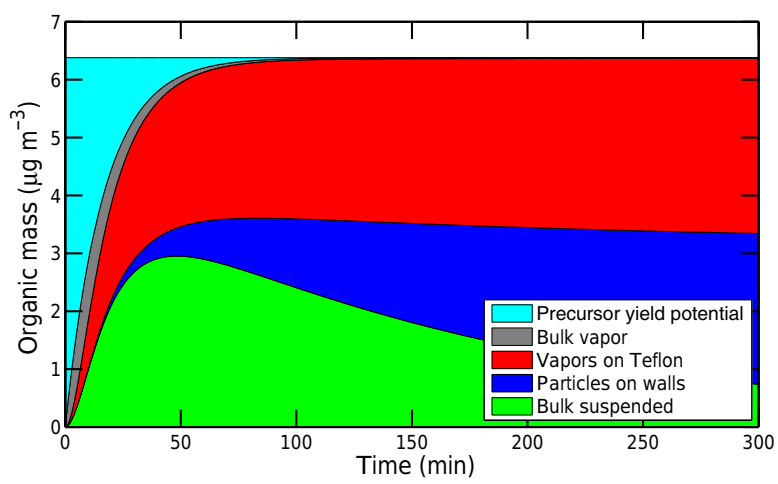

(b)

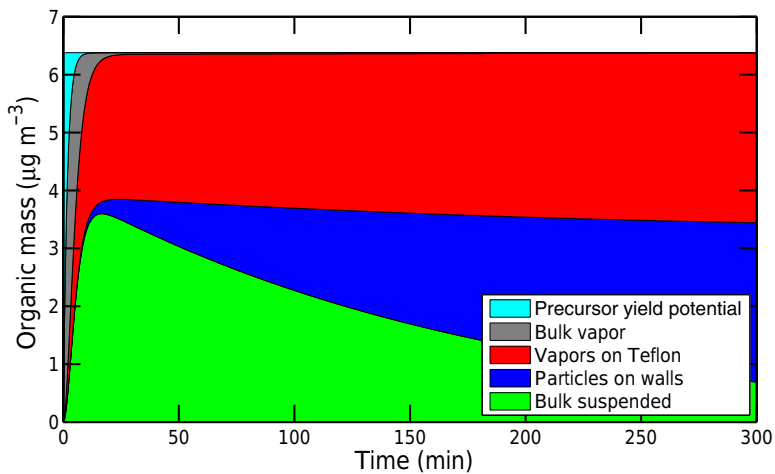

(c)

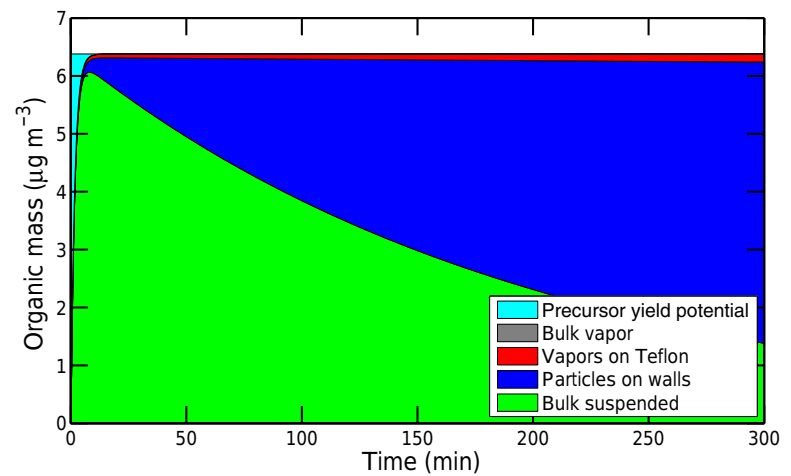

Figure 13. Locations of organic products from $3 \mathrm{ppb} \alpha$-pinene with varying concentrations of ozone and CS ratios: modest ozone, modest CS ratio (500 $\mathrm{ppb} \mathrm{O}_{3}$ with a $\mathrm{CS}$ ratio of $\left.1, \mathbf{a}\right)$; high ozone, modest CS ratio (5000 ppb $\mathrm{O}_{3}, \mathrm{CS}$ ratio of 1 , b); high ozone, high CS ratio (5000 ppb $\mathrm{O}_{3}$, CS ratio of $\left.100, \mathbf{c}\right)$. Given a seed concentration, increasing the ozone concentration causes $\alpha$-pinene to react faster, resulting in a higher condensation driving force and a higher organic particle mass after a shorter period. However, half of the vapors are still lost to the walls. By increasing the CS ratio, or seed concentration, by 2 orders of magnitude, all of the condensible vapors can be captured in the particle phase.

the walls as the run continues, as $C^{\mathrm{t}}$ grows while $C^{\mathrm{s}}+C^{\mathrm{d}}$ shrinks. However, we would like to avoid vapor wall losses altogether, if possible. Figure $13 \mathrm{c}$ shows that in theory it is possible to minimize the wall loss by increasing both the reaction rate and the condensation sink in the chamber. In this case, almost all of the organics condense to particles before slowly being lost to the walls. It is trivial to extrapolate the green condensed-phase concentration back to the "correct" value; unfortunately, this comes at the expense of running the chemistry extremely quickly, and potentially perturbing the gas-phase chemistry (especially the yields of HOMs due to autooxidation) and also almost certainly driving intense nucleation.

\section{Conclusion}

In this work, we took a dynamic one-dimensional volatility basis set model developed to model growth rates of freshly nucleated particles measured in CLOUD experiments at CERN and adapted it to $\alpha$-pinene ozonolysis experiments addressing SOA mass formation conducted in the CMU smog chamber. Based on the mass yield distribution from CLOUD, we found that our model overpredicts the organic mass produced and the resulting SOA mass yields over the course of these typical SOA formation experiments. However, we demonstrated that chamber experiments need to be treated dynamically, because there is a delay between the formation of low-volatility vapors and the condensation of these vapors to particles. This delay at least partially resolves the issue of the existence of low-volatility compounds that do not seem to show up in Odum plots - they exist, but show up at higher aerosol loading than expected because of the time it takes for them to condense.

We found that substantial oligomerization is consistent with both the CLOUD and the CMU chamber results. By allowing semivolatile organics in the condensed phase to form dimers with lower volatility compounds, we showed that it is possible to replicate the data from CLOUD experiments. It is likely that oligomerization plays a role in organic aerosol formation, but how substantial a role remains to be determined. Because of the many parameters available to explain the current set of observations (HOM yields, oligomer fraction, mass accommodation coefficients, vapor wall losses, $\mathrm{RO}_{2}$ autooxidation rates, etc.), only a very carefully designed series of experiments will fully constrain this problem. Whether high LVOCs or oligomerization is responsible 
for the CLOUD growth rates, we would expect to have observed nucleation in the CMU chamber experiments, where none occurred; this strongly suggests that the gas-phase product distributions in the two experiments are different, though the reasons remain uncertain.

We emphasize that the ratio of vapor-particle condensation sink to the vapor-wall loss sink is critical to interpretation of smog-chamber data. At low initial CS ratios, most of the organic vapors produced are lost to chamber walls. As the CS ratio increases, more of the mass goes to the particles, but the suspended mass concentration does not scale with the CS ratio. Because of particle wall loss, the organics on suspended particles are driven to the walls. For the same reason, the condensation sink to the remaining particles also decreases over time. Therefore, merely increasing the condensation sink does not always increase the concentration of bulk organic particle mass. Ideal chamber conditions require both high $\mathrm{CS}$ ratios and high oxidation rates (by boosting ozone concentrations). At high oxidation rates, all of the $\alpha$-pinene is immediately reacted into low-volatility compounds, and the high CS ratio allows these compounds to quickly condense onto seed particles. This allows all the organics to be collected onto seeds before wall losses in either the vapor or suspended phase can have a large effect. However, this condition may in turn interfere with the unimolecular gas-phase autooxidation chemistry that produces the HOMs in the first place. Consequently, direct measurements of the gas-phase HOM yields during such experiments are critical to the overall interpretation of the experimental data.

Code and data availability. The data and MATLAB code for this project are available in the Supplement. The code is also available at https://bitbucket.org/wchuang/vbs_dynamics_release, where there may be a more recent version of it.

\section{The Supplement related to this article is available online at https://doi.org/10.5194/acp-17-10019-2017- supplement.}

Competing interests. The authors declare that they have no conflict of interest.

Acknowledgements. This work was sponsored by the US National Science Foundation grant AGS 1447056.

Edited by: Kari Lehtinen

Reviewed by: two anonymous referees

\section{References}

Bilde, M. and Pandis, S. N.: Evaporation rates and vapor pressures of individual aerosol species formed in the atmospheric oxidation of alpha- and beta- pinene, Environ. Sci. Technol., 35, 33443349, https://doi.org/10.1021/es001946b, 2001.

Cocker III, D. R., Clegg, S. L., Flagan, R. C., and Seinfeld, J. H.: The effect of water on gas-particle partitioning of secondary organic aerosol. Part I: $\alpha$-pinene/ozone system, Atmos. Environ., 35, 6049-6072, https://doi.org/10.1016/S1352-2310(01)004046, 2001.

Crounse, J. D., Nielsen, L. B., Jørgensen, S., Kjaergaard, H. G., and Wennberg, P. O.: Autoxidation of organic compounds in the atmosphere, J. Phys. Chem. Lett., 4, 3513-3520, https://doi.org/10.1021/jz4019207, 2013.

Donahue, N. M., Robinson, A. L., Stanier, C. O., and Pandis, S. N.: Coupled partitioning, dilution, and chemical aging of semivolatile organics., Environ. Sci. Technol., 40, 2635-2643, https://doi.org/10.1021/es052297c, 2006.

Ehn, M., Thornton, J. A., Kleist, E., Sipilä, M., Junninen, H., Pullinen, I., Springer, M., Rubach, F., Tillmann, R., Lee, B., Lopez-Hilfiker, F., Andres, S., Acir, I.-H., Rissanen, M., Jokinen, T., Schobesberger, S., Kangasluoma, J., Kontkanen, J., Neiminen, T., Kurtén, T., Nielsen, L. B., Jørgensen, S., Kjaergaard, H. G., Canagaratna, M., Dal Maso, M., Berndt, T., Petäjä, T., Wahner, A., Kerminen, V.-M., Kulmala, M., Worsnop, D. R., Wildt, J., and Mentel, T. F.: A large source of lowvolatility secondary organic aerosol, Nature, 506, 476-479, https://doi.org/10.1038/nature13032, 2014.

Epstein, S. A., Riipinen, I., and Donahue, N. M.: A semiempirical correlation between enthalpy of vaporization and saturation concentration for organic aerosol, Environ. Sci. Technol., 44, 743748, https://doi.org/10.1021/es902497z, 2010.

Grieshop, A. P., Donahue, N. M., and Robinson, A. L.: Is the gas-particle partitioning in alpha-pinene secondary organic aerosol reversible?, Geophys. Res. Lett., 34, 1-5, https://doi.org/10.1029/2007GL029987, 2007.

Griffin, R. J., Cocker, D. R., Flagan, R. C., and Seinfeld, J. H.: Organic aerosol formation from the oxidation of biogenic hydrocarbons, J. Geophys. Res., 104, 3555-3567, 1999.

Haagen-Smit, A. J.: Chemistry and Physiology of Los Angeles Smog, Ind. Eng. Chem., 44, 1342-1346, 1952.

Hallquist, M., Wenger, J. C., Baltensperger, U., Rudich, Y., Simpson, D., Claeys, M., Dommen, J., Donahue, N. M., George, C., Goldstein, A. H., Hamilton, J. F., Herrmann, H., Hoffmann, T., Iinuma, Y., Jang, M., Jenkin, M. E., Jimenez, J. L., Kiendler-Scharr, A., Maenhaut, W., McFiggans, G., Mentel, Th. F., Monod, A., Prévôt, A. S. H., Seinfeld, J. H., Surratt, J. D., Szmigielski, R., and Wildt, J.: The formation, properties and impact of secondary organic aerosol: current and emerging issues, Atmos. Chem. Phys., 9, 5155-5236, https://doi.org/10.5194/acp9-5155-2009, 2009.

Heaton, K. J., Sleighter, R. L., Hatcher, P. G., Hall IV, W. A., and Johnston, M. V.: Composition domains in monoterpene secondary organic aerosol, Environ. Sci. Technol., 43, 7797-7802, https://doi.org/10.1021/es901214p, 2009.

Kalberer, M., Paulsen, D., Sax, M., Steinbacher, M., Dommen, J., Prévôt, A. S. H., Fisseha, R., Weingartner, E., Frankevich, V., Zenobi, R., and Baltensperger, U.: Identification of Polymers as 
Major Components of Atmospheric Organic Aerosols, Science, 303, 1659-1662, https://doi.org/10.1126/science.1092185, 2004. Kirkby, J., Duplissy, J., Sengupta, K., Frege, C., Gordon, H., Williamson, C., Heinritzi, M., Simon, M., Yan, C., Almeida, J., Tröstl, J., Nieminen, T., Ortega, I. K., Wagner, R., Adamov, A., Amorim, A., Bernhammer, A.-K., Bianchi, F., Breitenlechner, M., Brilke, S., Chen, X., Craven, J., Dias, A., Ehrhart, S., Flagan, R. C., Franchin, A., Fuchs, C., Guida, R., Hakala, J., Hoyle, C. R., Jokinen, T., Junninen, H., Kangasluoma, J., Kim, J., Krapf, M., Kürten, A., Laaksonen, A., Lehtipalo, K., Makhmutov, V., Mathot, S., Molteni, U., Onnela, A., Peräkylä, O., Piel, F., Petäjä, T., Praplan, A. P., Pringle, K., Rap, A., Richards, N. A. D., Riipinen, I., Rissanen, M. P., Rondo, L., Sarnela, N., Schobesberger, S., Scott, C. E., Seinfeld, J. H., Sipilä, M., Steiner, G., Stozhkov, Y., Stratmann, F., Tomé, A., Virtanen, A., Vogel, A. L., Wagner, A. C., Wagner, P. E., Weingartner, E., Wimmer, D., Winkler, P. M., Ye, P., Zhang, X., Hansel, A., Dommen, J., Donahue, N. M., Worsnop, D. R., Baltensperger, U., Kulmala, M., Carslaw, K. S., and Curtius, J.: Ion-induced nucleation of pure biogenic particles, Nature, 533, 521-526, https://doi.org/10.1038/nature17953, 2016.

Krechmer, J. E., Pagonis, D., Ziemann, P. J., and Jimenez, J. L. L.: Quantification of gas-wall partitioning in Teflon environmental chambers using rapid bursts of low-volatility oxidized species generated in-situ, Environ. Sci. Technol., 50, 5757-5765, https://doi.org/10.1021/acs.est.6b00606, 2016.

Kroll, J. H. and Seinfeld, J. H.: Representation of secondary organic aerosol laboratory chamber data for the interpretation of mechanisms of particle growth, Environ. Sci. Technol., 39, 4159-4165, https://doi.org/10.1021/es048292h, 2005.

Kroll, J. H. and Seinfeld, J. H.: Chemistry of secondary organic aerosol: Formation and evolution of low-volatility organics in the atmosphere, Atmos. Environ., 42, 3593-3624, https://doi.org/10.1016/j.atmosenv.2008.01.003, 2008.

Kurtén, T., Tiusanen, K., Roldin, P., Rissanen, M., Luy, J.-N., and Donahue, N. M.: Saturation Vapor Pressures of $\alpha$-pinene Autoxidation Products May Be Severely Underpredicted by Group Contribution Methods, J. Phys. Chem. A, 120, 2569-2582, https://doi.org/10.1021/acs.jpca.6b02196, 2016.

Lehtipalo, K., Rondo, L., Kontkanen, J., Schobesberger, S., Jokinen, T., Sarnela, N., Kürten, A., Ehrhart, S., Franchin, A., Nieminen, T., Riccobono, F., Sipilä, M., Yli-Juuti, T., Duplissy, J., Adamov, A., Ahlm, L., Almeida, J., Amorim, A., Bianchi, F., Breitenlechner, M., Dommen, J., Downard, A. J., Dunne, E. M., Flagan, R. C., Guida, R., Hakala, J., Hansel, A., Jud, W., Kangasluoma, J., Kerminen, V.-M., Keskinen, H., Kim, J., Kirkby, J., Kupc, A., Kupiainen-Määttä, O., Laaksonen, A., Lawler, M. J., Leiminger, M., Mathot, S., Olenius, T., Ortega, I. K., Onnela, A., Petäjä, T., Praplan, A., Rissanen, M. P., Ruuskanen, T., Santos, F. D., Schallhart, S., Schnitzhofer, R., Simon, M., Smith, J. N., Tröstl, J., Tsagkogeorgas, G., Tomé, A., Vaattovaara, P., Vehkamäki, H., Vrtala, A. E., Wagner, P. E., Williamson, C., Wimmer, D., Winkler, P. M., Virtanen, A., Donahue, N. M., Carslaw, K. S., Baltensperger, U., Riipinen, I., Curtius, J., Worsnop, D. R., and Kulmala, M.: The effect of acid-base clustering and ions on the growth of atmospheric nano-particles, Nat. Commun., 7, 11594, https://doi.org/10.1038/ncomms11594, 2016.

Matsunaga, A. and Ziemann, P. J.: Gas-Wall Partitioning of Organic Compounds in a Teflon Film Chamber and Potential Effects on Reaction Product and Aerosol Yield Measurements, Aerosol Sci. Tech., 44, 881-892, https://doi.org/10.1080/02786826.2010.501044, 2010.

McVay, R. C., Cappa, C. D., and Seinfeld, J. H.: Vapor - Wall Deposition in Chambers: Theoretical Considerations, Environ. Sci. Technol., 48, 10251-10258, 2014.

McVay, R. C., Zhang, X., Aumont, B., Valorso, R., Camredon, M., La, Y. S., Wennberg, P. O., and Seinfeld, J. H.: SOA formation from the photooxidation of a-pinene: systematic exploration of the simulation of chamber data, Atmos. Chem. Phys., 16, 2785 2802, https://doi.org/10.5194/acp-16-2785-2016, 2016.

Odum, J. R., Hoffmann, T., Bowman, F., Collins, D., Flagan, R. C., and Seinfeld, J. H.: Gas-Particle Partitioning and Secondary Organic Aerosol Yields, Environ. Sci. Technol., 30, 2580-2585, https://doi.org/10.1021/es950943+, 1996.

Pankow, J. F.: An Absorption Model Of The Gas/Aerosol Partitioning Involved In The Formation Of Secondary Organic Aerosol, Atmos. Environ., 28, 189-193, https://doi.org/10.1016/j.atmosenv.2007.10.060, 1994.

Pathak, R. K., Presto, A. A., Lane, T. E., Stanier, C. O., Donahue, N. M., and Pandis, S. N.: Ozonolysis of $\alpha$-pinene: parameterization of secondary organic aerosol mass fraction, Atmos. Chem. Phys., 7, 3811-3821, https://doi.org/10.5194/acp-7-3811-2007, 2007a.

Pathak, R. K., Stanier, C. O., Donahue, N. M., and Pandis, S. N.: Ozonolysis of $\alpha$-pinene at atmospherically relevant concentrations: Temperature dependence of aerosol mass fractions (yields), J. Geophys. Res.-Atmos., 112, 1-8, https://doi.org/10.1029/2006JD007436, 2007b.

Presto, A. A. and Donahue, N. M.: Investigation of alphapinene + ozone secondary organic aerosol formation at low total aerosol mass, Environ. Sci. Technol., 40, 3536-3543, https://doi.org/10.1021/es052203z, 2006.

Presto, A. A., Hartz, K. E. H., and Donahue, N. M.: Secondary organic aerosol production from terpene ozonolysis. 1. Effect of UV radiation, Environ. Sci. Technol., 39, 7036-7045, 2005.

Rissanen, M. P., Kurtén, T., Sipilä, M., Thornton, J. A., Kangasluoma, J., Sarnela, N., Junninen, H., Jørgensen, S., Schallhart, S., and Kajos, M. K.: The Formation of Highly Oxidized Multifunctional Products in the Ozonolysis of Cyclohexene, J. Am. Chem. Soc., 136, 15596-15606, 2014.

Robinson, E. S., Saleh, R., and Donahue, N. M.: Organic aerosol mixing observed by single-particle mass spectrometry, J. Phys. Chem. A, 117, 13935-13945, https://doi.org/10.1021/jp405789t, 2013.

Saleh, R., Donahue, N. M., and Robinson, A. L.: Time scales for gas-particle partitioning equilibration of secondary organic aerosol formed from alpha-pinene ozonolysis, Environ. Sci. Technol., 47, 5588-5594, https://doi.org/10.1021/es400078d, 2013.

Sheehan, P. E. and Bowman, F. M.: Estimated effect of temperature on secondary organic aerosol concentrations, Environ.Sci.Technol., 35, 2129_ 2135https://doi.org/10.1021/es001547g, 2001.

Shilling, J. E., Chen, Q., King, S. M., Rosenoern, T., Kroll, J. H., Worsnop, D. R., McKinney, K. A., and Martin, S. T.: Particle mass yield in secondary organic aerosol formed by the dark ozonolysis of $\alpha$-pinene, Atmos. Chem. Phys., 8, 2073-2088, https://doi.org/10.5194/acp-8-2073-2008, 2008. 
Shilling, J. E., Chen, Q., King, S. M., Rosenoern, T., Kroll, J. H., Worsnop, D. R., DeCarlo, P. F., Aiken, A. C., Sueper, D., Jimenez, J. L., and Martin, S. T.: Loading-dependent elemental composition of a-pinene SOA particles, Atmos. Chem. Phys., 9, 771-782, https://doi.org/10.5194/acp-9-771-2009, 2009.

Shiraiwa, M., Yee, L. D., Schilling, K. A., Loza, C. L., Craven, J. S., Zuend, A., Ziemann, P. J., and Seinfeld, J. H.: Size distribution dynamics reveal particle-phase chemistry in organic aerosol formation, P. Natl. Acad. Sci. USA, 110, 11746-11750, https://doi.org/10.1073/pnas.1307501110, 2013.

Song, C., Zaveri, R. A., Alexander, M. L., Thornton, J. A., Madronich, S., Ortega, J. V., Zelenyuk, A., Yu, X. Y., Laskin, A., and Maughan, D. A.: Effect of hydrophobic primary organic aerosols on secondary organic aerosol formation from ozonolysis of alpha-pinene, Geophys. Res. Lett., 34, 1-5, https://doi.org/10.1029/2007GL030720, 2007.

Tolocka, M. P., Jang, M., Ginter, J. M., Cox, F. J., Kamens, R. M., and Johnston, M. V.: Formation of Oligomers in Secondary Organic Aerosol, Environ. Sci. Technol., 38, 1428-1434, https://doi.org/10.1021/es035030r, 2004.

Tröstl, J., Chuang, W. K., Gordon, H., Heinritzi, M., Yan, C., Molteni, U., Ahlm, L., Frege, C., Bianchi, F., Wagner, R., Simon, M., Lehtipalo, K., Williamson, C., Craven, J. S., Duplissy, J., Adamov, A., Almeida, J., Flagan, R. C., Franchin, A., Fuchs, C., Guida, R., Gysel, M., Pet, T., Steiner, G., Tomé, A., Virtanen, A., Wagner, A. C., Weingartner, E., Wimmer, D., Winkler, P. M., Ye, P., Carslaw, K. S., Curtius, J., Dommen, J., Kirkby, J., Kulmala, M., Riipinen, I., Worsnop, D. R., Donahue, N. M., and Baltensperger, U.: The role of low-volatility organic compounds for initial particle growth in the atmosphere, Nature, 533, 527531, https://doi.org/10.1038/nature18271, 2016.
Trump, E. R. and Donahue, N. M.: Oligomer formation within secondary organic aerosols: equilibrium and dynamic considerations, Atmos. Chem. Phys., 14, 3691-3701, https://doi.org/10.5194/acp-14-3691-2014, 2014.

Trump, E. R., Epstein, S. A., Riipinen, I., and Donahue, N. M.: Wall Effects in Smog Chamber Experiments: A Model Study, Aerosol Sci. Tech., 50, 1180-1200, https://doi.org/10.1080/02786826.2016.1232858, 2016.

Vaden, T. D., Imre, D., Beránek, J., Shrivastava, M., and Zelenyuk, A.: Evaporation kinetics and phase of laboratory and ambient secondary organic aerosol, P. Natl. Acad. Sci. USA, 108, 21902195, https://doi.org/10.1073/pnas.1013391108, 2011.

Ye, P., Ding, X., Hakala, J., Hofbauer, V., Robinson, E. S., and Donahue, N. M.: Vapor wall loss of semi-volatile organic compounds in Teflon chamber, Aerosol Sci. Tech., 50, 822-834, https://doi.org/10.1080/02786826.2016.1195905, 2016a.

Ye, P., Ding, X., Ye, Q., Robinson, E. S., and Donahue, N. M.: Uptake of Semivolatile Secondary Organic Aerosol Formed from $\alpha$-Pinene into Nonvolatile Polyethylene Glycol Probe Particles, J. Phys. Chem. A, 120, 1459-1467, https://doi.org/10.1021/acs.jpca.5b07435, 2016b.

Zhang, X., Cappa, C. D., Jathar, S. H., Mcvay, R. C., Ensberg, J. J., Kleeman, M. J., and Seinfeld, J. H.: Influence of vapor wall loss in laboratory chambers on yields of secondary organic aerosol, P. Natl. Acad. Sci. USA, 111, 5802-5807, https://doi.org/10.1073/pnas.1404727111, 2014. 